\title{
Form and Function of the M4 Cell, an Intrinsically Photosensitive Retinal Ganglion Cell Type Contributing to Geniculocortical Vision
}

\author{
Maureen E. Estevez, ${ }^{1}$ P. Michelle Fogerson, ${ }^{1}$ Marissa C. Ilardi, ${ }^{1}$ Bart G. Borghuis, ${ }^{2}$ Eric Chan, ${ }^{1}$ Shijun Weng, ${ }^{1}$ \\ Olivia N. Auferkorte, ${ }^{1}$ Jonathan B. Demb, ${ }^{2,3}$ and David M. Berson ${ }^{1}$ \\ ${ }^{1}$ Department of Neuroscience, Brown University, Providence, Rhode Island 02912, and 2Department of Ophthalmology and Visual Science and \\ ${ }^{3}$ Department of Cellular and Molecular Physiology, Yale University School of Medicine, New Haven, Connecticut 06510
}

\begin{abstract}
The photopigment melanopsin confers photosensitivity upon a minority of retinal output neurons. These intrinsically photosensitive retinal ganglion cells (ipRGCs) are more diverse than once believed, comprising five morphologically distinct types, M1 through M5. Here, in mouse retina, we provide the first in-depth characterization of M4 cells, including their structure, function, and central projections. M4 cells apparently correspond to $\mathrm{ON} \alpha$ cells of earlier reports, and are easily distinguished from other ipRGCs by their very large somata. Their dendritic arbors are more radiate and highly branched than those of M1, M2, or M3 cells. The melanopsin-based intrinsic photocurrents of M4 cells are smaller than those of M1 and M2 cells, presumably because melanopsin is more weakly expressed; we can detect it immunohistochemically only with strong amplification. Like M2 cells, M4 cells exhibit robust, sustained, synaptically driven ON responses and dendritic stratification in the $\mathrm{ON}$ sublamina of the inner plexiform layer. However, their stratification patterns are subtly different, with $\mathrm{M} 4$ dendrites positioned just distal to those of $\mathrm{M} 2$ cells and just proximal to the $\mathrm{ON}$ cholinergic band. M4 receptive fields are large, with an $\mathrm{ON}$ center, antagonistic OFF surround and nonlinear spatial summation. Their synaptically driven photoresponses lack direction selectivity and show higher ultraviolet sensitivity in the ventral retina than in the dorsal retina, echoing the topographic gradient in S- and M-cone opsin expression. M4 cells are readily labeled by retrograde transport from the dorsal lateral geniculate nucleus and thus likely contribute to the pattern vision that persists in mice lacking functional rods and cones.
\end{abstract}

\section{Introduction}

The earliest studies of intrinsically photosensitive retinal ganglion cells (ipRGCs) focused on a single cell type, now called "M1," with dendrites stratifying in the outermost stratum of the inner plexiform layer (IPL) (Berson et al., 2002; Hattar et al., 2002). Soon thereafter, two additional morphologically and physiological distinct varieties of ipRGCs emerged, the M2 and M3 cells, revealed by anti-melanopsin immunohistochemistry, melanopsin-reporter transgenesis, retrograde labeling from pupillary reflex centers, and intracellular recording and dye filling

Received March 22, 2012; revised July 12, 2012; accepted July 28, 2012.

Author contributions: M.E.E. and D.M.B. designed research; M.E.E., P.M.F., M.C.I., B.G.B., E.C., S.W., O.N.A., and J.B.D. performed research; D.M.B. contributed unpublished reagents/analytic tools; M.E.E., M.C.I., B.G.B., E.C., J.B.D., and D.M.B. analyzed data; M.E.E. and D.M.B. wrote the paper.

This work was funded by NIH Grants F32-EY021994 to M.E.E., R01-EY012793 to D.M.B., R01-EY014454 to J.B.D., and NSF Grant I2011104359 to P.M.F. We thank Isaiah Berson for programming the receptive field stimulus. We also thank Soile Nymark, Rikard Frederiksen, Carter Cornwall, and Jordan Renna for technical advice; Dianne Boghossian and Kimberly Boghossian for assistance maintaining and genotyping mice; and Matthew Van Hook, Kevin Baruzzi, and Lauren Quattrochi for support with data and analysis.

The authors declare no competing financial interests.

Correspondence should be addressed to Dr. Maureen Estevez, Department of Neuroscience, Box GL-N, Brown University, Providence, RI 02912. E-mail: estevez@brown.edu.

E. Chan's present address: Rockefeller University, New York, NY.

S. Weng's present address: Fudan University, Shanghai, China.

0. N. Auferkorte's present address: Max-Planck-Institute for Brain Research, Frankfurt, Germany.

DOI:10.1523/JNEUROSCI.1422-12.2012

Copyright $\odot 2012$ the authors $\quad 0270-6474 / 12 / 3213608-13 \$ 15.00 / 0$
(Warren et al., 2003; Dacey et al., 2005; Viney et al., 2007; Baver et al., 2008; Schmidt and Kofuji, 2009; Berson et al., 2010; Ecker et al., 2010). The M2 subtype has a large radiate dendritic field that stratifies in the ON sublamina of the IPL and exhibits stronger synaptically driven responses and weaker intrinsic responses than the $\mathrm{M} 1$ cell. The M3 cell is bistratified with dendrites terminating in both the ON and OFF layers of the IPL. They are rare and may not represent a unique cell type as their dendrites do not tile the retina (Berson et al., 2010); physiologically, they closely resemble M2 cells (Schmidt and Kofuji, 2011).

Recently, cre-lox mouse lines were developed that mark melanopsin-expressing cells with greatly improved sensitivity (Hatori et al., 2008; Brown et al., 2010; Ecker et al., 2010), permitting the identification of two new ipRGC types, M4 and M5 (Ecker et al., 2010). Although they lacked detectable antimelanopsin immunofluorescence, both types exhibited intrinsic photocurrents, albeit weakly. These improved reporter mice also revealed an expanded set of retinofugal targets of ipRGCs, including the dorsal lateral geniculate nucleus (dLGN) and superior colliculus (Brown et al., 2010; Ecker et al., 2010). This suggested a potential role in pattern vision for ipRGCs, further supported by the persistence of crude pattern discrimination and light-evoked responses in the dLGN and visual cortex in mice lacking functional rods and cones (Brown et al., 2010; Ecker et al., 2010). These findings, which were anticipated by earlier anatomical data in primates (Dacey et al., 2005), challenge the prevailing view that 
ipRGCs contribute solely to "non-image-forming" visual centers and homeostatic, reflexive responses to ambient light. Understanding the role of ipRGCs in pattern vision requires, in part, a better understanding of the novel ipRGC types innervating pattern vision centers. To this end, we present here the first detailed description of M4 cells and the first direct confirmation that they project heavily to the dLGN. We also characterize their dendritic morphology and stratification, their intrinsic light responses, and synaptically driven receptive field properties. We find that M4 cells form a homogenous ganglion cell population distinguishable from all other known ipRGC subtypes by virtue of their unique anatomical and physiological properties.

\section{Materials and Methods}

Animals. All experiments were conducted in accordance with NIH guidelines under protocols approved by the Brown University (Providence, RI) or Yale University (New Haven, CT) Animal Care and Use Committee. Both male and female adult mice (6 weeks to 4 months old) were used. Nearly all experiments, unless otherwise noted, were conducted in

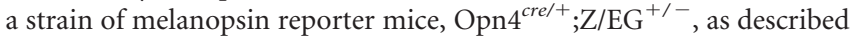
by Ecker et al., 2010. Briefly, this line was generated by crossing two mouse lines: (1) Opn $4^{\mathrm{Cre} / \mathrm{Cre}}$, kindly donated by Dr. Samer Hattar (Johns Hopkins University), in which the gene for Cre recombinase replaces both alleles of the melanopsin gene (Opn4); and (2) Z/EG ${ }^{+/-}$(The Jackson Laboratory, stock no. 003920), which expresses a transgene driven by the $\beta$-actin/CMV promoter and a floxed $\beta$-galactosidaseSTOP sequence followed by a sequence encoding EGFP. Cre-mediated recombination excises the $\beta$-galactosidase-STOP sequence and triggers EGFP expression, labeling melanopsin-expressing cells with higher sensitivity than earlier reporter lines (Hattar et al., 2002; Schmidt et al., 2008; Do et al., 2009). In some experiments (Figs. 3C,F, 6C), Opn $4^{\mathrm{Cre} / \mathrm{Cre}} ; \mathrm{Zl}$ $\mathrm{EG}^{+/-}$mice (which express EGFP in ipRGCs, but do not express melanopsin) were used to test physiological responses of M4 cells in the absence of melanopsin.

Retrograde labeling. Mice were anesthetized with isoflurane (3\% in oxygen) and placed in a stereotaxic apparatus. Body temperature, respiration rate, and depth of anesthesia were monitored throughout the procedure. Body temperature was maintained with a heating pad. Cholera toxin $\beta$-subunit conjugated to Alexa Fluor $594(5 \mu \mathrm{g} / \mu \mathrm{l} ; \sim 0.5 \mu \mathrm{l})$ was injected under stereotaxic guidance into the dLGN through a micropipette coupled to a pneumatic pressure source (Picospritzer; Parker Hannifin). At least $24 \mathrm{~h}$ after injection mice were killed by $\mathrm{CO}_{2}$ inhalation and cervical dislocation. Brains were removed, submerged in $4 \%$ paraformaldehyde overnight, rinsed with phosphate-buffered saline, and embedded in $4 \%$ agarose. Brains were then sectioned on a vibrating microtome at 50 $\mu \mathrm{m}$ in the coronal plane and mounted on glass slides. Injection sites were assessed by epifluorescence microscopy.

Tissue preparation and solutions. Animals were typically dark adapted for $\geq 3 \mathrm{~h}$ before eyes were harvested for recording. We ultimately concluded that the epifluorescence illumination needed to target cells in vitro caused such strong light adaptation (see Fig. 5) that prior dark adaptation was without benefit, so we dispensed with this step in later studies devoted to receptive field analysis and recordings from retrolabeled cells. Mice were killed by $\mathrm{CO}_{2}$ asphyxiation. Under dim red light, eyes were enucleated after making a small cautery mark on the dorsal cornea. A large relieving cut was made in the dorsal eyecup to facilitate later identification of retinal orientation. The retina was removed and bathed in Ames' medium (Sigma) supplemented with $23 \mathrm{~mm} \mathrm{NaHCO}_{3}$ and $10 \mathrm{~mm}$ D-glucose and bubbled with $95 \% \mathrm{O}_{2} / 5 \% \mathrm{CO}_{2}$ at room temperature. The whole retina was placed ganglion cell side up in a glass chamber, mounted with a slice anchor (Warner Instruments), and superfused at 2 $\mathrm{ml} / \mathrm{min}$ with the gassed Ames' solution maintained at $30-35^{\circ} \mathrm{C}$ unless otherwise noted with a temperature controller (ATR-4, Quest Scientific or TC-324B, Warner Instruments). Intracellular solutions used for electrophysiological recordings contained (in $\mathrm{mm}$ ): $120 \mathrm{~K}$-gluconate (for current clamp) or Cs-methanesulfonate (for voltage clamp), $5 \mathrm{NaCl}, 4$ $\mathrm{KCl}$, or $\mathrm{CsCl}, 2$ EGTA, 10 HEPES, 4 ATP-Mg, 7 phosphocreatine-Tris, 0.3 GTP-Tris, and 2 QX-314 (for voltage clamp only), $\mathrm{pH} 7.3,270-280$
mOsm. Intracellular solutions for electrophysiological recordings in Figure 8 contained (in $\mathrm{mm}$ ): 120 Cs-methanesulfonate, 5 TEA-Cl, 10 HEPES, 10 BAPTA, 3 NaCl, 2 QX-314-Cl, 4 ATP-Mg, 0.4 GTP-Na and 10 phosphocreatine, $\mathrm{pH} 7.3,280 \mathrm{mOsm}$. For all whole-cell recordings, Lucifer yellow or Alexa Fluor 488 hydrazide was added to the recording pipette solution to permit morphological characterization of the recorded cell. To block transmission of signals from conventional outer retinal photoreceptors to the inner retina, we bath applied a drug cocktail described previously (Wong et al., 2005, 2007) consisting of $100 \mu \mathrm{M} \mathrm{L}-(+)$-2-amino4-phosphonobutyric acid (L-AP4, a group III metabotropic glutamate receptor agonist), $40 \mu \mathrm{M}$ 6,7-dinitroquinoxaline-2,3-dione (DNQX, AMPA/ kainate receptor antagonist), and $30 \mu \mathrm{M} \mathrm{D}-(-)$-2-amino-5-phosphonopentanoic acid (D-AP5, NMDA receptor antagonist). Drug concentrations for the cocktail used in Figure $8 D$ were $100 \mu \mathrm{M}$ DNQX, $100 \mu \mathrm{M}$ D-AP5, $50 \mu \mathrm{M}$ L-AP4, $50 \mu \mathrm{M}$ SR-95531, and $2 \mu \mathrm{M}$ strychnine.

Patch-clamp physiology. Whole-cell patch-clamp recordings of isolated flat-mount retinae were performed as described previously (Wong et al., 2005, 2007; Van Hook and Berson, 2010) using an Axopatch 700B amplifier, Digidata 1322 digitizer, and pClamp 9.2 data acquisition software (Molecular Devices). Sampling frequency was $10 \mathrm{kHz}$, and recordings were low-pass filtered at $4 \mathrm{kHz}$. Pipettes were pulled from thick-walled borosilicate tubing with a Flaming/Brown P-97 pipette puller (Sutter Instruments); tip resistances were 4-8 M $\Omega$ when filled with internal solution. Unless otherwise noted, series resistance for voltage-clamp experiments was not compensated, and experiments were discarded if the series resistance exceeded $30 \mathrm{M} \Omega$. Cells were voltage clamped at $-64 \mathrm{mV}$ after correction for liquid junction potential (measured to be $-6.6 \mathrm{mV}$ for the standard internal solution).

Presumptive ipRGCs were identified by EGFP fluorescence evoked by blue ( $460-500 \mathrm{~nm})$ mercury epifluorescence excitation and viewed by an upright microscope equipped with a water immersion lens $(20 \times$ or $40 \times)$ and cooled CCD camera. The total duration of epi-illumination was usually $\sim 30 \mathrm{~s}$ and never more than $1 \mathrm{~min}$. The excitation light had an intensity of $6 \cdot 10^{16}$ photons $\cdot \mathrm{cm}^{-2} \cdot \mathrm{s}^{-1}$ at $480 \mathrm{~nm}$. We estimate that this bleaches $99 \%$ of cone photoreceptor visual pigment according to the relation $F=1-\exp (-I P t)$, where $F$ is the fraction of pigment bleached, $I$ is the intensity of the light, $t$ is duration of light exposure in seconds, and $P$ is the photosensitivity of cones $\left(7.5 \cdot 10^{-9} \mu \mathrm{m}^{2}\right.$, (Nikonov et al., 2006; Kolesnikov et al., 2011).

After a cell was identified by epifluorescence, we used infrared optics to establish the patch recording. For this purpose, the retina was illuminated from below by the microscope's tungsten-halogen illuminator passed through a long-pass spectral filter and viewed through the CCD camera. We used a patch pipette to tear a small hole in the inner limiting membrane overlying the targeted cell, then guided a fresh patch pipette to the exposed cell, established a G $\Omega$ seal, and ruptured the membrane with suction. A period of at least $30 \mathrm{~min}$ separated epifluorescence viewing and testing a cell's light responses; except for the infrared viewing, this period passed in complete darkness.

Electroretinogram. These experiments were performed as described elsewhere (Nymark et al., 2005; Heikkinen et al., 2008). The isolated retina was placed photoreceptor side down in a specimen holder with upper and lower chambers, each containing a $\mathrm{Ag}-\mathrm{AgCl}$ electrode for recording the trans-retinal potential. The upper (ganglion cell) side was superfused with oxygenated and heated Ames' solution identical to that described above for patch-clamp experiments, with the addition of $2 \mathrm{~mm}$ $\mathrm{L}$-aspartic acid to block synaptic transmission to second-order neurons and therefore eliminate the b-and c-wave components of the electroretinogram (ERG). The lower (photoreceptor) side chamber contained HEPES-buffered Ames' solution ( $\mathrm{pH} 7.4$ with $\mathrm{NaOH}$ ). The signal was amplified $10000 \times$, low-pass filtered at $300 \mathrm{~Hz}$, and digitized at $5 \mathrm{kHz}$.

Light stimulation. Diffuse light stimuli for patch-clamp experiments were delivered episcopically by a $100 \mathrm{~W}$ xenon lamp. The beam passed through an electronically controlled shutter and dual filter wheels (MAC 5000, Ludl Electronic Products) equipped with neutral density and bandpass filters. Irradiances were measured with a radiometer (S370, UDT Instruments). The intensity of unattenuated light at $360,480,500$, and $600 \mathrm{~nm}$ was $1.41 \cdot 10^{16}, 1.15 \cdot 10^{17}, 1.20 \cdot 10^{17}$, and $1.20 \cdot 10^{17}$ photons $\mathrm{cm}^{-2} \cdot \mathrm{s}^{-1}$, respectively. For studies of extrinsic, synaptically driven photoresponses, we used $1 \mathrm{~s}$ stimuli and interstimulus intervals ranging 
from $1 \mathrm{~min}$ (for the lowest intensity) to $5 \mathrm{~min}$ (for the highest intensity). To probe intrinsic, melanopsin-based photoresponses, we used 5 or $10 \mathrm{~s}$ light steps and interstimulus intervals ranging from $2 \mathrm{~min}$ (for the lowest intensity) to $10 \mathrm{~min}$ (for the highest intensity).

Light stimuli for ERG experiments were generated by a tungstenhalogen lamp passed through a narrow-band spectral filter $(500 \mathrm{~nm}$ peak; $10 \mathrm{~nm}$ full width at half-height) and attenuated with neutral density filters. Flashes were full field and $20 \mathrm{~ms}$ in duration, controlled by an electronic shutter.

Patterned light stimuli for receptive field studies in Figure 7 were generated by custom software developed in Psychophysics Toolbox and Matlab. These were delivered through a LCD projector (Optoma EP719) and focused by an accessory lens onto a sheet of ground glass displaced just slightly from the focal plane of one of the microscope's two camera ports. This displacement was adjusted so that the water-immersion $20 \times$ objective lens used to visualize the recorded cell focused a highly demagnified image of the ground glass approximately $150 \mu \mathrm{m}$ distal to the objective's focal plane. This arrangement permitted us to switch at will and without intervening focal adjustments between viewing a sharp image of the recorded cell body and patch pipette tip and delivering patterned stimuli focused near the level of rod and cone outer segments. Stimuli consisted of flashed spots and annuli, drifting bars, and drifting or contrast-reversing sinusoidal gratings. Michelson contrast of the gratings was $95 \%$.

For experiments shown in Figure 8, stimuli consisted of contrastreversing square wave gratings that were generated as described previously (Wang et al., 2011) with a video projector (M109s DLP Projector; Dell) custom fitted with a UV LED (NC4U134A, peak wavelength, 385 $\mathrm{nm}$; Nichia) focused onto the retina's photoreceptor layer through the condenser lens of the microscope. The stimulus wavelength was about equally efficient at stimulating $\mathrm{M}$ and $\mathrm{S}$ opsins and thus gave a relatively uniform stimulation of coexpressing M-/S-cones along the dorsalventral axis of the mouse retina (Wang et al., 2011). Stimulus intensity at the retina was $1.4 \cdot 10^{13}$ photons $\cdot \mathrm{cm}^{-2} \cdot \mathrm{s}^{-1}$, equivalent to $2.8 \times 10^{4}$ photoisomerizations $\left(R^{*}\right) /$ cone/s (assuming a $1 \mu \mathrm{m}^{2}$ collecting area for the cone).

Intracellular dye injections. Single EGFP-labeled ipRGCs were filled by intracellular iontophoretic dye injection with Lucifer yellow or Neurobiotin using sharp micropipettes, as described elsewhere (Pu et al., 1994). All cells included in the analysis were brightly filled to the tips of their dendrites. In some cases, neighboring M2 and M4 ipRGCs were filled with contrasting dyes to permit assessments of the relative levels of dendritic stratification of their overlapping dendrites: Lucifer yellow alone was injected in one cell and a mixture of Alexa Fluor 594 hydrazide and Lucifer yellow in the other.

Antibodies. The following primary antibodies were used: goat polyclonal anti-choline acetyl transferase (ChAT; Millipore) and rabbit polyclonal anti-melanopsin (Advanced Targeting Systems). For secondary antibodies we used Alexa Fluor 594 or 647 donkey anti-goat IgG as well as Alexa Fluor donkey anti-rabbit 594 (Invitrogen). In some cases, as described in more detail below, we increased the sensitivity of melanopsin immunodetection by tyramide signal amplification with horseradish peroxidase (HRP)-tagged goat anti-rabbit IgG and Alexa Fluor 594 tyramide (TSA-15, Invitrogen).

Immunohistochemistry. Retinas were fixed for $1 \mathrm{~h}$ (for anti-ChAT) or overnight (for anti-melanopsin) in $4 \%$ paraformaldehyde (PFA) in $0.1 \mathrm{M}$ phosphate buffer, washed $(6 \times 10 \mathrm{~min})$ in $0.1 \mathrm{M}$ PBS, and incubated overnight in blocking solution (2\% Triton X-100 and 5\% donkey serum in PBS at $4^{\circ} \mathrm{C}$ ). They were then incubated for two days at $4^{\circ} \mathrm{C}$ in primary antibody at dilutions of 1:200 (for ChAT) or 1:10,000 (for melanopsin) in blocking solution. Retinas were washed in PBS $(6 \times 10 \mathrm{~min})$ then incubated in secondary antibody $(1: 200)$ for $2-4 \mathrm{~h}$ at $4^{\circ} \mathrm{C}$. Retinas were washed in PBS $(3 \times 15 \mathrm{~min})$, mounted on glass slides, and coverslipped using Aqua-Mount or ProLong Gold mounting medium (Invitrogen).

To increase the sensitivity of the melanopsin immunoreactivity, we used tyramide signal amplification, which utilizes the catalytic activity of horseradish peroxidase to generate high density labeling of a target protein. All procedures followed the manufacturer's protocol (TSA-15, In- vitrogen; http://probes.invitrogen.com/media/pis/mp20911.pdf) and were performed at room temperature, unless otherwise noted. The retina was fixed overnight and washed in PBS as described above. Endogenous peroxidase activity was quenched by incubating the retina in $1 \% \mathrm{H}_{2} \mathrm{O}_{2}$ and $0.5 \%$ Triton-X in PBS for $1 \mathrm{~h}$, followed by washing in PBS $(3 \times 10$ $\mathrm{min}$ ). The tissue was placed in TSA-15 blocking solution for $2 \mathrm{~h}$ and then incubated with melanopsin antibody at 1:10,000 in TSA-15 blocking solution for $\sim 36 \mathrm{~h}$ at $4^{\circ} \mathrm{C}$. The tissue was washed in PBS $(6 \times 10 \mathrm{~min})$, blocked in TSA-15 blocking solution for $1 \mathrm{~h}$, and then incubated with goat-anti-rabbit HRP secondary antibody at 1:100 in TSA-15 blocking solution. After washing in PBS $(6 \times 10 \mathrm{~min})$, retinae were then incubated exactly 5 min with tyramide-594 at 1:100 in $1 \times$ Plus Amplification Diluent (PerkinElmer), quickly transferred to PBS $(3 \times 10 \mathrm{~min})$, and mounted on glass slides with ProLong Gold (Invitrogen).

Image analysis. Cells were imaged and photographed as described previously (Berson et al., 2010; Ecker et al., 2010) with a SPOT RT Slider digital microscope camera (Diagnostic Instruments). Cell profiles were traced in Adobe Photoshop CS3 to create 2-D reconstructed drawings. Soma diameter, dendritic field length, total dendritic length, and branch points were measured using ImageJ software (http://imagej.nih.gov) as reported previously (Berson et al., 2010). Diameters of dendritic fields and cell bodies were obtained for each cell by calculating the diameter of a circle having the same area as a convex polygon minimally enclosing the dendritic or somatic profile. All such somatic measurements were made on images obtained at focal planes passing through the cell and at exposure times just long enough to reveal crisply defined cell margins without appreciable bloom. Sholl analysis was performed using the Sholl Analysis Plugin (version 1.0) for ImageJ, which is freely available online (http://biology.ucsd.edu/labs/ghosh/software/).

Confocal images at various depths (" $\mathrm{z}$-stacks") were acquired with a Zeiss LSM 510 Meta laser scanning microscope and analyzed using Zeiss LSM Image Browser software and ImageJ. Images were adjusted for contrast and brightness and, in some cases, pseudo-colored for clarity. In general, all image adjustments were global. However, in some cells we manually deleted blood vessel artifacts, and for the dye-filled cell pair shown in Figure $2 C$, we nulled the green Lucifer yellow channel (green) for the M4 cell, which had been filled with a mixture of Lucifer yellow and Alexa-594 to enhance the contrast with the M2 cell, which had been filled with Lucifer yellow alone. We developed a custom ImageJ macro to derive from these $\mathrm{z}$-stacks quantitative assessments of the depth of stratification of dendrites of dye-filled ganglion cells relative to the ChAT bands. The user selected points on the distal dendrites (i.e., >50 micrometers from the soma) for which there was clearly a single $z$-plane of best focus. The macro logged the $x, y$, and $z$ coordinates of each selected point, with $z$ corresponding to the plane of best focus. For each point, the macro then calculated for each $z$-plane the average pixel intensity for red and green channels individually within a square of 40 pixels (corresponding to $8.7 \mu \mathrm{m}$ ) on a side and centered on the point's $x$ and $y$ coordinates. These intensity profiles were brought into register in depth (correcting for imperfect tissue flatness) by normalizing the $z$-values to the userdefined plane of best dendritic focus. In effect, this manipulation corrected for imperfect tissue flatness by assuming that the terminal dendrites were perfectly monostratified within a narrow IPL sublamina. While this was undoubtedly not strictly true, this approach yielded much tighter distributions of depth values for the ChAT bands than were evident in the raw (non-normalized) depth values, and thus provides a better estimate of the mean relative displacement of the terminal dendrites from the ChAT bands.

Statistical analysis. Data analysis and statistics were performed using Clampfit 9.2 (Molecular Devices) and Origin 6.0 (Microcal Software). Unless otherwise noted, data are expressed as mean \pm SEM, and data were considered significant when $p<0.05$, as determined using an independent two-tailed Student's $t$ test.

\section{Results}

To identify ipRGCs for dye-filling and recording, we used the Opn $4^{\mathrm{Cre} /+} ; \mathrm{Z} / \mathrm{EG}^{+/-}$mouse line, in which all known types of ipRGCs express EGFP (Ecker et al., 2010). M4 cells could be targeted with very high reliability by aiming for the largest fluo- 
A
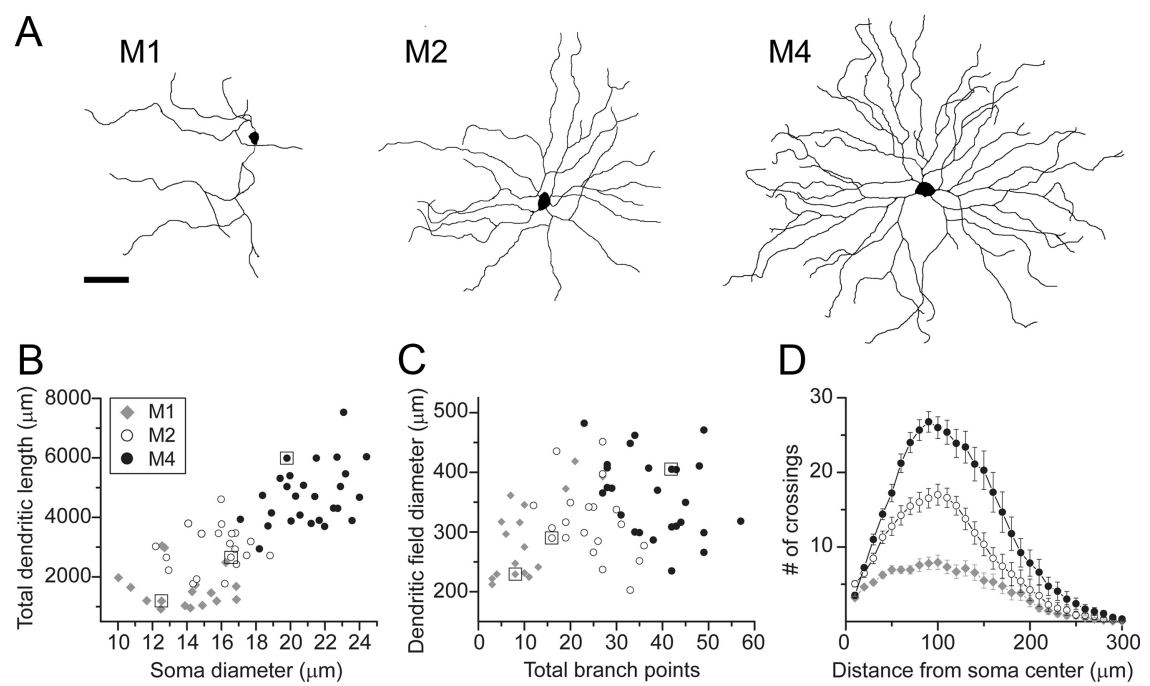

Figure 1. Morphology of three types of ipRGCs expressing the EGFP reporter in $0 \mathrm{pnn}^{\mathrm{Cre} /+} ; \mathrm{Z} / \mathrm{EG}{ }^{+/-}$mice as revealed by intracellular dye. $A$, Tracings of representative ipRGCs of the M1 (left), M2 (middle), and M4 types (right) as viewed in whole-mount retina. $\boldsymbol{B}, \boldsymbol{C}$, Comparison of these ipRGC types in plots of total dendritic length versus soma diameter $(\boldsymbol{B})$ and of dendritic field diameter versus total number of branch points $(\boldsymbol{C})(\mathrm{M} 1, n=17 ; \mathrm{M} 2, n=20$ and $M 4, n=27)$. Key in $\boldsymbol{B}$ applies to panels $\boldsymbol{B}-\boldsymbol{D}$. The small square boxes surrounding select data points in $\boldsymbol{B}$ and $\boldsymbol{C}$ indicate the representative cells depicted in $\boldsymbol{A}$. $\boldsymbol{D}$, Sholl analysis of dendritic arbors for $\mathrm{M} 1(n=16), \mathrm{M} 2(n=17)$, and M4 cells $(n=18)$, plotting the number of dendritic branches present at various distances from the soma. Samples include cells filled during whole-cell patch-clamp recordings as well as by sharp electrode intracellular dye injections. Error bars indicate SEM. Scale bar, $50 \mu \mathrm{m}$.

Table 1. Group data on the morphology of three types of ipRGCs

\begin{tabular}{lccc}
\hline & M1 $(n=17)$ & M2 $(n=20)$ & M4 $(n=27)$ \\
\hline Soma diameter $(\mu \mathrm{m})$ & $13.9 \pm 0.5^{* * *}$ & $15.7 \pm 0.4^{* * *}$ & $21.0 \pm 0.4$ \\
Dendritic-field diameter $(\mu \mathrm{m})$ & $290.1 \pm 16.5^{* *}$ & $316.6 \pm 13.8^{*}$ & $359.6 \pm 12.8$ \\
Total dendritic length $(\mu \mathrm{m})$ & $1605 \pm 162^{* * *}$ & $2957 \pm 164^{* * *}$ & $4751 \pm 193$ \\
Total branch points & $10.2 \pm 1.6^{* * *}$ & $24.4 \pm 1.5^{* * *}$ & $38.2 \pm 1.6$ \\
No. of primary dendrites & $3.0 \pm 0.2^{* * *}$ & $4.2 \pm 0.3^{* *}$ & $5.3 \pm 0.2$ \\
\hline
\end{tabular}

Values listed are mean \pm SE. Asterisks indicate statistically significant difference from values for M4 cells $\left({ }^{*} p<\right.$ $0.05 ; * *_{0}<0.01 ; * *{ }^{*} p<0.001$.

rescent cell bodies. Relatively weak EGFP fluorescence was also characteristic of these cells.

\section{Somadendritic profile}

Our initial goal was to expand upon the preliminary morphological characterization of the M4 ipRGC type (Berson et al., 2010; Ecker et al., 2010). We dye filled these cells by iontophoresis through sharp micropipettes or by dialysis during whole-cell patch-clamp recording. We analyzed the morphology of $27 \mathrm{M} 4$ cells and, for comparison, samples of two better-known ipRGC types, the M1 cells $(n=17)$ and M2 cells $(n=20)$; none of these cells were included in our earlier reports. Figure $1 A$ illustrates representative dendritic profiles of the three ipRGC types and highlights several features of M4 cells that distinguish them from M1 and M2 cells, including their larger somata and dendritic fields and their more extensively branching dendritic arbors.

These differences and others are quantified for the full sample of filled cells in Table 1. Cell bodies of M4 cells were among the largest of any mouse ganglion cells, averaging $21 \mu \mathrm{m}$ in diameter. They were significantly larger $(p<0.001)$ than those of either M1 cells (mean diameter, $\sim 14 \mu \mathrm{m})$ or M2 cells $(\sim 16 \mu \mathrm{m})$. In fact, there was almost no overlap between the soma sizes of the M4 and M2 cells in our sample, and none at all between M4 and M1 cells (Fig. $1 B$ ).

The dendritic field diameter of M4 cells $(\sim 360 \mu \mathrm{m})$ was significantly larger than that of both M1 cells $(\sim 290 \mu \mathrm{m}, p<0.01)$ and M2 cells $(\sim 317 \mu \mathrm{m}, p<0.05)$. The proximal dendrites of M4 cells invariably appeared thicker in caliber than those of $\mathrm{M} 1$ and $\mathrm{M} 2$ cells, and their axons also appeared stouter. M4 cells also had more complex dendritic arbors than M1 and M2 cells by a variety of measures. First, they had a much larger number of branch points (means: $\sim 38$ for M4 cells, $\sim 24$ for M2 cells, and $\sim 10$ for M1 cells; $p<$ 0.001). M4 cells also exhibited much greater total dendritic length (means: $\sim 4750 \mu \mathrm{m}$ as compared to $\sim 2960 \mu \mathrm{m}$ for M2 cells and $\sim 1610 \mu \mathrm{m}$ for M1 cells; $p<$ $0.001)$. The greater dendritic complexity of M4 cells was confirmed by Sholl analysis, in which concentric rings centered on the soma are overlaid on the dendritic profile, and the total number of dendritic crossings is assessed for each ring. The resulting Sholl plots (Fig. 1D) were broadly similar in shape for the three cell types, with the mean of number of intersections peaking at $\sim 100 \mu \mathrm{m}$ from the soma. However, the plot for M4 cells was scaled dramatically upward, with M4 cells possessing nearly twice as many dendrites at any distance from the soma as M2 cells and nearly four times as many as M1 cells. To summarize, the M4 type of ipRGCs can be distinguished from the M1 and M2 types by their larger soma size and their larger, more highly branched dendritic arbors.

\section{Dendritic stratification}

The dendrites of M4 cells are monostratified within the ON sublamina of the IPL (Ecker et al., 2010). In this respect, they resemble the M2 cells but differ from the M1 cells, which stratify in the outermost OFF sublayer, and from the bistratified M3 cells. We sought more precise information about the depth of M4 dendritic stratification, including whether these cells costratify with M2 cells. We dye filled M4 and M2 cells in vitro and then processed the retinal whole mounts for anti-ChAT immunofluorescence to reveal the two cholinergic plexuses, which are widely used as depth markers in the IPL. We then acquired and analyzed confocal z-stacks of these whole mounts to assess the depth of M4 and M2 dendrites in relation to the ON ChAT band.

Representative M4 and M2 cells from this analysis are shown in Figure 2, $A$ and $B$, respectively. The top images in these two panels show projected images of the somadendritic profiles of the two cells (Lucifer yellow fluorescence is shown in green). The bottom panels show a view of the image data digitally rotated 90 degrees to reveal the distribution of processes in depth. The dendritic stratification of the M4 cell is at first glance very similar to that of the M2 cell; both occupy the lower half of the ON sublayer of the IPL, somewhat below (vitreal to) the ON ChAT band. Closer examination, however, suggests a subtle difference in stratification; whereas the M4 dendrites appeared to abut the lower border of the ON ChAT band (Fig. $2 A$ ), a discernable gap separated the ON ChAT band and M2 dendrites in many places (Fig. 2B).

To determine whether this was a consistent difference in stratification, we carried out a quantitative analysis of five M4 cells (Fig. 2D) and four M2 cells (Fig. 2E). For a large number of points in the distal dendritic arbor of these cells, we derived from 
confocal $\mathrm{Z}$-stacks the displacement in depth of the ON ChAT band (which appears as the major peak in the red curve) from the plane of best dendritic focus. For M2 cells (Fig. 2E), the displacement was 3-4 slices in the $\mathrm{z}$-stack, corresponding to about $2 \mu \mathrm{m}$; for M4 cells (Fig. 2D), the offset was only about half as large.

As further validation of this apparent difference in stratification, we filled neighboring M2 and M4 cells with contrasting intracellular dyes and analyzed the relative depth of their distal dendrites wherever their projected profiles intersected. Five cell pairs were studied in this way. An example of one such pair is shown in Figure $2 C$; the rotated view below is consistent with the foregoing depth analysis. From such pairs, we analyzed 69 instances of intersections between the M2 and M4 dendritic profiles. As summarized in the histogram in Figure $2 F$, in the great majority of these cases the M4 dendrites lay above (distal to) the M2 dendrite (45/69 instances; 65\%). When this was not true, typically no difference in depth could be discerned between the dendrites of the two cells (18/69 crossings; $26 \%$ ). Instances in which the M4 dendrite lay below (vitread) to the M2 dendrites were very rare (6/69 cases; 9\%). Collectively, these data demonstrate a subtle but consistent difference in stratification between these cell types within the ON sublayer of the IPL, summarized in Figure $3 G$, with M4 cells stratifying just above the M2 cells and just beneath the ON ChAT band. This difference is of potential functional significance because it suggests likely distinctions between M4 and M2 cells in their synaptic inputs from specific bipolar and amacrine cell types. For example, M4 dendrites are well positioned to make contacts with the axon terminals of Type 7 ON cone bipolar cells, while M2 cells are more likely to receive input from Type 8 (Wässle et al., 2009).

\section{Melanopsin immunoreactivity}

Anti-melanopsin immunostaining clearly marks M1-M3 types of ipRGCs (Hatori et al., 2008; Berson et al., 2010; Ecker et al., 2010), but has not yet been detected in identified M4 cells. This leaves open the possibility that the weak photoresponses of M4 cells under synaptic blockade are not actually mediated by intrinsic melanopsin-based phototransduction, but rather by some indirect influence from melanopsin-expressing retinal ganglion cells (RGCs) that is resistant to this blockade, perhaps involving gap junctions. Alternatively, the highly amplifying cre-lox system may be capable of reporting a level of melanopsin expression that is too low to be detected by conventional immunofluorescence; indirect evidence supports this view (Berson et al., 2010). To provide more definitive evidence on this point, we filled M4 cells
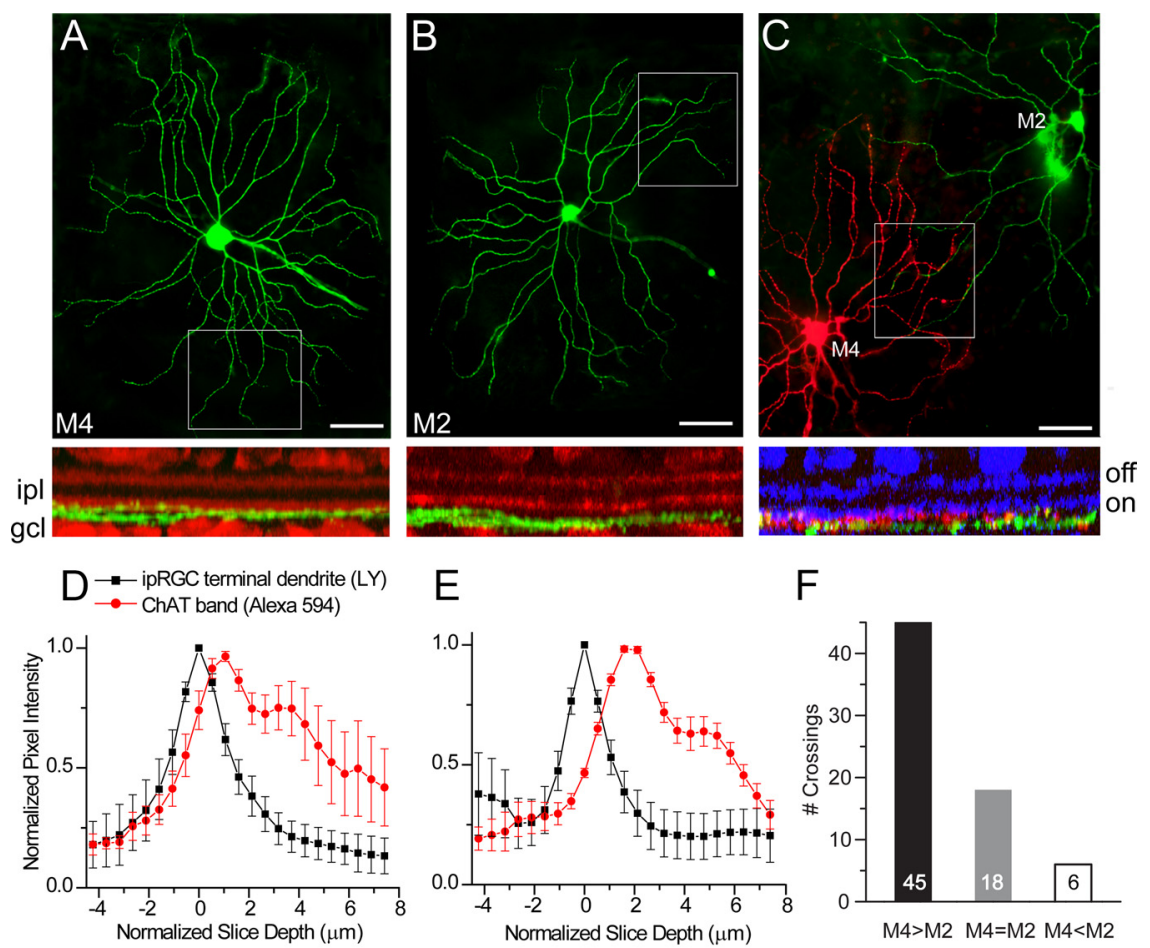

E

$\mathrm{F}$
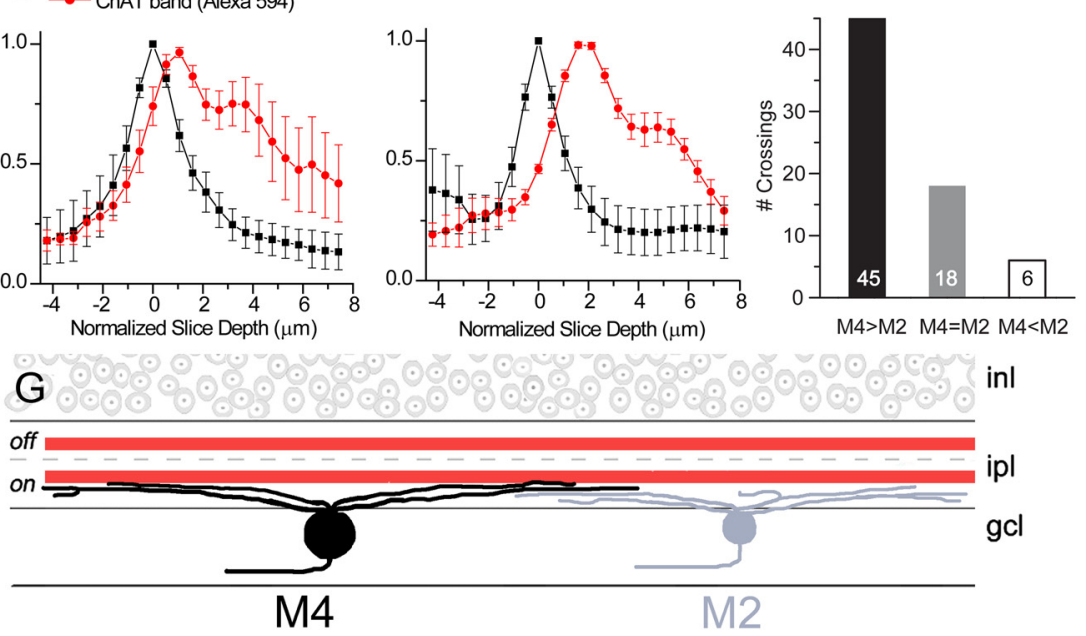

Figure 2. Evidence that the dendrites of $M 4$ cells stratify just distal (sclerad) to those of $M 2$ cells within the $0 \mathrm{~N}$ sublayer of the IPL. $\boldsymbol{A}, \boldsymbol{B}$, Top, Fluorescence images from wholemount retinae showing an M4 cell $(\boldsymbol{A})$ and an M2 cell $(\boldsymbol{B})$ filled with Lucifer yellow (green). Bottom, Digitally rotated views of the sample zones indicated above (rectangular outlines) to show the stratification of $M 4$ $(\boldsymbol{A})$ and $\mathrm{M} 2(\boldsymbol{B})$ distal dendrites in relation to the ChAT-immunoreactive processes (red). Both types ramify slightly below the $0 \mathrm{~N}$ ChAT band, but the M2 cell appears to have a slightly greater downward displacement. C, Direct comparison of the dendritic stratification of an M2 cell (green) and an overlapping M4 cell (red) filled with contrasting fluorescent dyes by sharp electrode intracellular injections. The rotated image below is as in $\boldsymbol{A}$ and $\boldsymbol{B}$, except that the anti-ChAT immunofluorescence is shown in blue, M2 dendrites in green, and M4 dendrites in red. Scale bars: $\boldsymbol{A}-\boldsymbol{C}, 50 \mu \mathrm{m} . \boldsymbol{D}, \boldsymbol{E}$, Quantification of confocal data collected as in $\boldsymbol{A}$ and $\boldsymbol{B}$ for a population of $\mathrm{M} 4$ cells ( $\boldsymbol{D} ; n=5$ cells, 2 spots sampled per terminal dendrite, $38-54$ dendritic locations per cell) and $M 2$ cells of the ChAT signal (red curve) is plotted as a function of its displacement from the peak of the dendritic signal of the ipRGC (normalized to $z=0$; black curve). The offset in depth between ipRGC terminal dendrites and the ON ChAT band (which appears as the major peak in the red curve) is $\sim 1 \mu \mathrm{m}$ for M4 cells and twice that for M2 cells. Error bars indicate SEM. LY, Lucifer yellow.F, Bar graph indicating the relative stratification of $M 4$ and $M 2$ dendrites revealed by analysis of points of overlap in the distal dendritic arbors of paired M2 plus M4 cells, filled with contrasting dyes as in C. M4 dendrites nearly always lay sclerad to the overlapping M2 M2 process ("M4 $<M 2$ "). Data are from 69 points of overlap among 5 paired M4-M2 injections. G, schematic representation of the dendritic stratification of M4 cells (black) within the IPL, with terminal dendrites lying just below the ON ChAT band (red) and just above the dendrites of M2 cells (gray). inl, Inner nuclear layer; ipl, inner plexiform layer; gcl, ganglion cell layer.

with intracellular dye and then processed the tissue with antimelanopsin antibodies, in some cases using tyramide signal amplification to enhance the immunofluorescence. Figure 3 demonstrates a series of such experiments. The left panel in Figure $3 A$ shows a Lucifer yellow fill (green) of a very large EGFP ${ }^{+}$ ganglion cell in an Opn $4^{\mathrm{Cre} /+} ; \mathrm{Z} / \mathrm{EG}^{+/-}$mouse retina. The large soma, characteristic dendritic profile, and stratification in the ON sublayer (data not shown) confirmed its identity as an M4 cell. Further, under synaptic blockade, the cell responded to light with a modest depolarization and increased spike frequency (Fig. $3 D$ ), as is typical of M4 cells (see below, The intrinsic light re- 


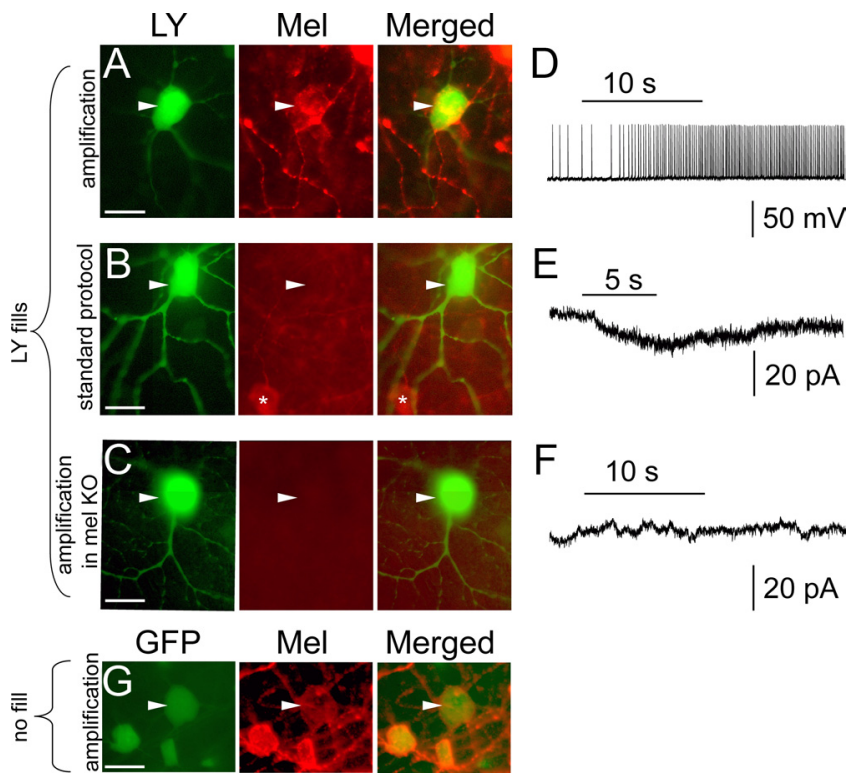

Figure 3. Immunohistochemical evidence for the presence of melanopsin protein in M4 cells. $\boldsymbol{A}-\boldsymbol{F}$, Tyramide-amplified, anti-melanopsin (Mel) immunofluorescence (red) is apparent in an M4 cell initially identified by its large, $\mathrm{EGFP}^{+}$cell body $\left(0 \mathrm{pn}^{\mathrm{Cre} /+} ;{ }^{+} / \mathrm{EG}^{+/-}\right.$mouse) and further confirmed as an M4 cell based on its Lucifer yellow (LY)-filled dendritic arbor (green; arbor not shown) and intrinsic photosensitivity under synaptic blockade $(\boldsymbol{A}, \boldsymbol{D}$; current clamp; horizontal bar denotes the $10 s, 480 \mathrm{~nm}$ light stimulus). Melanopsin immunostaining is not apparent in an $\mathrm{M} 4$ cell from a mouse of the same genotype if tyramide signal amplification is omitted $(\boldsymbol{B}, \boldsymbol{E})$ or if tyramide amplification is used, but the melanopsin gene has been knocked out ( $C, F ; 0 \mathrm{pn} 4^{(\mathrm{re} / \mathrm{Bre} ;} ; \mathrm{Z} / \mathrm{EG}^{+/-}$mouse). Recordings in $\boldsymbol{E}$ and $\boldsymbol{F}$ were done in voltage clamp. $\boldsymbol{G}$, A large $\mathrm{M} 4$ soma that was not filled or recorded expresses EGFP (green; left; $0 \mathrm{pn}^{\mathrm{Cre} /+} ; \mathrm{Z} / \mathrm{EG}^{+/-}$), and melanopsin immunoreactivity using tyramideamplification (red; middle). Collectively, these data indicate that melanopsin protein can be detected in $\mathrm{M} 4$ cells immunohistochemically provided the signal is amplified using tyramide $(\boldsymbol{A})$. Arrowheads indicate location of $\mathrm{M} 4$ cells. Asterisks indicate neighboring melanopsin immunopositive ipRGCS, probably M2 cells. Scale bars, $20 \mu \mathrm{m}$.

sponse of M4 cells: sensitivity and spectral tuning). Tyramideamplified immunofluorescence clearly revealed melanopsin immunostaining in this cell (Fig. $3 A$, middle, arrowhead). Such immunolabeling was not detectable in M4 cells by conventional immunofluorescence (i.e., without tyramide; Fig. $3 B ; n=2$ ), although neighboring M2 cells were visible (Fig. $3 B$, asterisk). Collectively, eight of nine physiologically confirmed and dyefilled M4 cells (89\%) were melanopsin immunopositive when tyramide amplification was used. Finally, in Figure $3 C$ we confirmed the specificity of the tyramide-amplified immunolabeling by repeating the experiment in Fig. $3 A$ in melanopsin-knockout

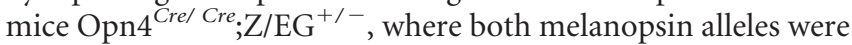
replaced by Cre so that ipRGCs expressed EGFP but not melanopsin; the loss of melanopsin was confirmed by the absence of an intrinsic light response (Fig. 3F). All tyramide-amplified immunolabeling was abolished in such retinae ( $n=4$; Fig. $3 C$, middle). Collectively, these data confirm that M4 cells do indeed express melanopsin, but at levels that are only detectible immunohistochemically when specialized amplification methods are used.

The intensity, distribution, and texture of tyramide-amplified melanopsin immunostaining was variable among large, EGFP ${ }^{+}$ presumptive M4 somata in the Opn $4^{\mathrm{Cre} /+} ;{\mathrm{Z} / \mathrm{EG}^{+/-}}$retina. Somatic immunofluorescence ranged from very faint with uniform texture (as in Fig. 3G, middle, arrowhead) to moderately faint with blotchy/nonuniform texture (as in Fig. $3 \mathrm{~A}$, middle, arrowhead). Immunofluorescence generally appeared concentrated in the plasma membrane and did not extend beyond the soma and primary dendrites.

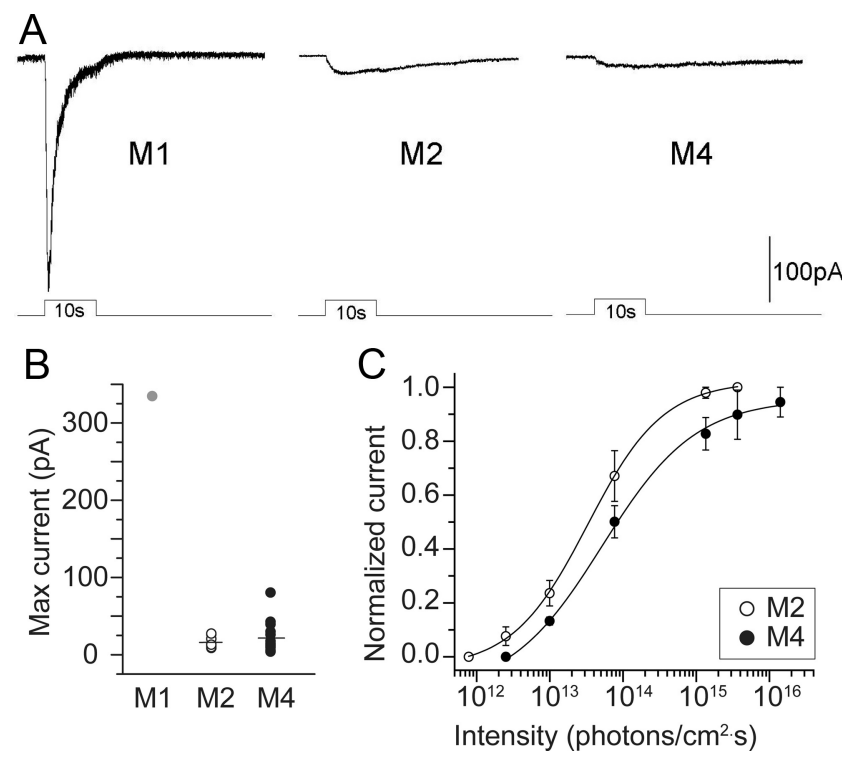

Figure 4. Comparison of melanopsin-driven intrinsic light responses of M1, M2, and M4 ipRGCs in $0 \mathrm{pn} 4^{\mathrm{Cre} /+} ; \mathrm{Z} / \mathrm{EG}^{+/-}$mice. $A$, Whole-cell voltage-clamp recordings of light-evoked currents in typical M1, M2, and M4 ipRGCs during pharmacological blockade of retinal synapses (stimulus: $480 \mathrm{~nm}, 10 \mathrm{~s}$, $1.2 \cdot 10^{17}$ photons $\cdot \mathrm{cm}^{-2} \cdot \mathrm{s}^{-1}$ ). B, Maximum (Max) photocurrents, evoked as in $\boldsymbol{A}$, in M1 (gray circle), M2 (open circles), and M4 (black circles) cells. C, Intensity-response relations were constructed from photoresponse families to light steps ( $480 \mathrm{~nm}, 5 \mathrm{~s}$ ), normalized to the peak response, averaged, and fitted with a logistic dose-response function. The $\mathbb{I R}_{50}$ (light intensity yielding half-maximal response) is $3.5 \cdot 10^{13}$ photons $\cdot \mathrm{cm}^{-2} \cdot \mathrm{s}^{-1}$ for $\mathrm{M} 2$ cells $(n=4)$ and $8.5 \cdot 10^{13}$ photons $\cdot \mathrm{cm}^{-2} \cdot \mathrm{s}^{-1}$ for M4 cells $(n=4)$. Error bars indicate SEM.

\section{The intrinsic light response of M4 cells: sensitivity and spectral tuning}

We next characterized the intrinsic light responses of these cells using whole-cell voltage-clamp recordings and compared their sensitivity to those of the M1 and M2 types of ipRGCs. Figure $4 \mathrm{~A}$ shows representative photocurrents for an M1 (left), an M2 (middle), and an M4 cell (right) evoked by a saturating light step $\left(480 \mathrm{~nm} ; 1.2 \cdot 10^{17}\right.$ photons $\left.\cdot \mathrm{cm}^{-2} \cdot \mathrm{s}^{-1} ; 10 \mathrm{~s}\right)$ while pharmacologically blocking retinal synapses. Consistent with previous reports (Schmidt and Kofuji, 2009, 2011), the M1 cell exhibited a much larger photocurrent than either the M2 or the M4 cell. In this example, the M4 cell had a weaker intrinsic response than the M2 cell, but this difference was not consistent among a larger sample. Group data from Figure $4 B$ confirmed that M2 and M4 cells have weaker intrinsic responses than M1 cells, but revealed no significant difference in the average maximal intrinsic photocurrent between M2 and M4 cells (M2: $-16.3 \pm 2.7 \mathrm{pA}, n=$ 8; M4: $-22.0 \pm 3.8 \mathrm{pA}, n=21, p=0.4)$. However, our average intrinsic response value for $\mathrm{M} 2$ cells from this study is below that measured by Schmidt and Kofuji (2009) $(-63.5 \pm 6.5 \mathrm{pA}, n=19)$. This may reflect a gene dose effect; their mice carried two melanopsin alleles, whereas ours have only one. M4 cells exhibited more variability in photocurrent amplitude (range, 4-80 pA) than did M2 cells $(10-27 \mathrm{pA})$, which may reflect greater variability in the amount of melanopsin expressed (see above, Melanopsin immunoreactivity). In pilot studies on rat retina, we found similar low amplitude intrinsic light responses in ganglion cells with M4-like morphology ( $n=2$, data not shown).

To evaluate the relative sensitivity of the intrinsic response in M2 and M4 cells, we measured the peak photocurrents evoked by light steps of various intensities $\left(10^{11}-10^{17}\right.$ photons $\cdot \mathrm{cm}^{-2} \cdot \mathrm{s}^{-1}$; $5 \mathrm{~s} ; 480 \mathrm{~nm})$. There was a trend toward lower sensitivity for the M4 cells $\left(0.5 \log\right.$ unit difference, mean $\mathrm{M} 4 \mathrm{IR}_{50}=3.5 \cdot 10^{13}$ 
photons $\cdot \mathrm{cm}^{-2} \cdot \mathrm{s}^{-1}, n=4$ versus mean $\mathrm{M} 2 \mathrm{IR}_{50}=8.5 \cdot 10^{13}$ photons $\cdot \mathrm{cm}^{-2} \cdot \mathrm{s}^{-1}, n=4$; Fig. $\left.4 C\right)$. However, the distribution of $\mathrm{IR}_{50}$ (irradiance yielding half-maximal responses) values among M4 cells was not statistically different from that for M2 cells $(p=0.3)$.

We tested the spectral tuning of the intrinsic response in five M4 cells with whole-field stimuli matched for photon flux. All were tested with at least three wavelengths: $400 \mathrm{~nm}, 480 \mathrm{~nm}$, and either 520 or $540 \mathrm{~nm}$; two were tested with one or more additional intermediate wavelengths. In every case, the $480 \mathrm{~nm}$ stimulus evoked the largest response (data not shown). This spectral behavior matches that of the intrinsic responses of other ipRGCs (e.g., Berson et al., 2002) and supports the view that melanopsin is the photopigment mediating these responses (e.g., Panda et al., 2005; Qiu et al., 2005).

\section{Synaptically driven light responses: assessment of outer retinal sensitivity}

We next sought to characterize the synaptically driven responses of M4 cells mediated by rods and cones. We suspected that the sensitivity of the outer retina was compromised in our preparation, because the retina was isolated from the retinal pigment epithelium and had to be exposed to $\sim 30$ s of bright epiillumination to permit identification of the EGFP-tagged M4 cell. We therefore assessed the sensitivity of the outer retina before and after such light exposure using the ERG. Synaptic transmission to second-order retinal neurons was blocked with $2 \mathrm{~mm}$ $\mathrm{L}$-aspartic acid, revealing, in isolation, the a-wave of the ERG, which reports the activity of rods and cones. Figure $5, A$ and $B$, each show a family of ERGs from the same isolated flat-mount retina. Figure $5 A$ shows a family of ERGs taken from a darkadapted retina that, before recording, had been exposed only to the dim red light used for dissection. This retina was then exposed to $30 \mathrm{~s}$ of bright blue epi-illumination, identical to that used for identifying EGFP ${ }^{+}$cells $\left(460-500 \mathrm{~nm}, \sim 6 \cdot 10^{16}\right.$ photons $\left.\cdot \mathrm{cm}^{-2} \cdot \mathrm{s}^{-1}\right)$. Immediately after such light exposure, the outer retina was completely unresponsive to light flashes, and the ERG was flat (data not shown). Responsiveness and sensitivity gradually recovered, reaching steady state after $\sim 30 \mathrm{~min}$, when the data of Figure $5 B$ were obtained.

A rough indication of the reduction in outer retinal sensitivity after the bleach and $30 \mathrm{~min}$ of recovery can be obtained by comparing the bold black traces in Figure $5, A$ and $B$, which were evoked by the same intensity of light $\left(3 \cdot 10^{13}\right.$ photons $\cdot$ $\left.\mathrm{cm}^{-2} \cdot \mathrm{s}^{-1}\right)$. A more complete assessment is possible from Figure $5 C$, which plots intensity-response relations from the flash response families before the bleach and after $30 \mathrm{~min}$ of recovery (as shown in Fig. $5 A, B$ ), as well as from responses (data not shown) recorded $60 \mathrm{~min}$ after the bleach. These curves reveal a persistent reduction of $\sim 2 \log$ units in outer retinal sensitivity after the epifluorescence illumination. Based on these data, all subsequent experiments were designed so that no more than $30 \mathrm{~s}$ of blue epi-illumination was used to find M4 cells, and the retina was left 30 min in the dark after the epi-illumination to achieve the maximal recovery of sensitivity before testing synaptically mediated light responses.

\section{Synaptically driven light responses: kinetics and spectral tuning}

When synaptic blockers were omitted from the bath, M4 cells exhibited large, brisk $\mathrm{ON}$ responses to full-field steps of light (Fig. $6 A, B$ ). These synaptically mediated photocurrents (Fig. 6A,C) began with a sharp and rapid inward transient peak that decayed
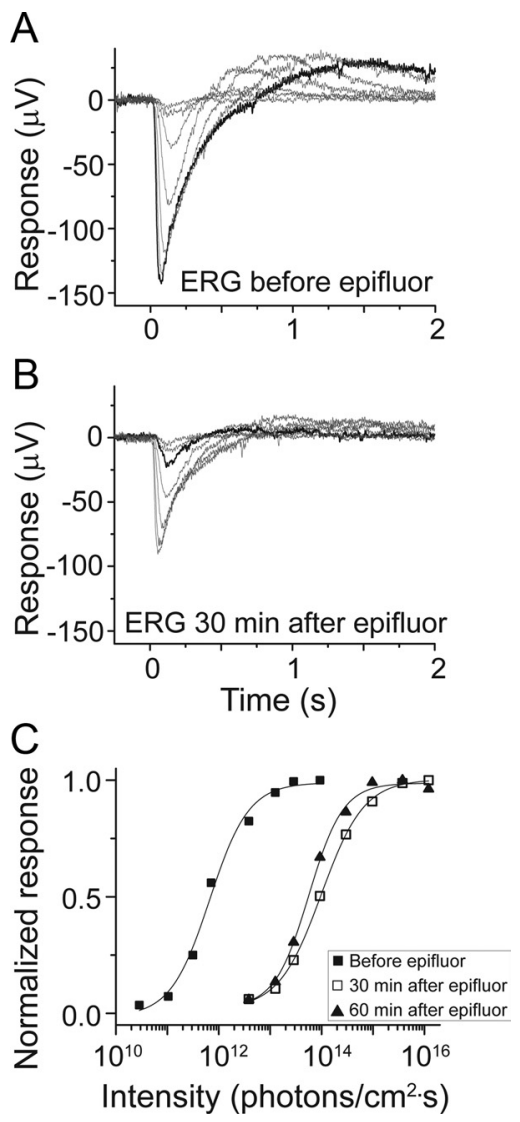

Figure 5. Assessment of outer retinal sensitivity as revealed by the electroretinogram, ERG, in $0 \mathrm{pn} 4^{\mathrm{Cre} /+} ; \mathrm{Z} / \mathrm{EG}^{+/-}$mice before and after the epi-illumination used to reveal EGFP. $A, B$, ERG a-wave response families of whole-mount isolated retina to 20 ms flashes of $500 \mathrm{~nm}$ light before $(\boldsymbol{A})$ and 30 $\min$ after $(\boldsymbol{B})$ a 30 s full-field exposure to blue epi-fluorescence illumination ( $460-500 \mathrm{~nm}, 6 \cdot 10^{16}$ photons $\cdot \mathrm{cm}^{-2} \cdot \mathrm{s}^{-1}$, yielding a $99 \%$ bleach as estimated by calculation). Flash intensities differed by $0.5 \log$ unit increments, ranging from $10^{10}-10^{13}$ photons $\cdot \mathrm{cm}^{-2} \cdot \mathrm{s}^{-1}$ in $A$ and $10^{12}-10^{16}$ photons $\cdot \mathrm{cm}^{-2} \cdot \mathrm{s}^{-1}$ in $\boldsymbol{B}$. The bold black traces in $\boldsymbol{A}$ and $\boldsymbol{B}$ indicate the response under these conditions to stimuli of matched intensity $\left(20 \mathrm{~ms} ; 500 \mathrm{~nm} ; 3 \cdot 10^{13}\right.$ photons $\left.\cdot \mathrm{cm}^{-2} \cdot \mathrm{s}^{-1}\right)$. $C$, Intensity-response relations constructed from the flash response families in $\boldsymbol{A}$ and $\boldsymbol{B}$ (black and open squares, respectively), as well as from responses (data not shown) recorded $60 \mathrm{~min}$ after the bleach (black triangles). These reveal about a 2 log unit reduction in outer retina sensitivity after the epifluorescence illumination. Data were normalized to the peak response and fitted with a logistic doseresponse function. The light intensity yielding half-maximal response $\left(\mathbb{R}_{50}\right)$ was $7 \cdot 10^{11}$ photons . $\mathrm{cm}^{-2} \cdot \mathrm{s}^{-1}$ before the bleach, $1 \cdot 10^{14}$ photons $\cdot \mathrm{cm}^{-2} \cdot \mathrm{s}^{-1} 30$ min after the bleach, and $6 \cdot 10^{13}$ photons $\cdot \mathrm{cm}^{-2} \cdot \mathrm{s}^{-1} 60 \mathrm{~min}$ after the bleach.

within a second to a current which was unusually sustained. For example, when evoked by 1 s light steps $>1$ log unit above threshold, the photocurrent invariably lasted for the full stimulus duration ( $n=20$ cells), and this was wavelength independent (tested: 360, 480, 500, and $600 \mathrm{~nm}$ ). Indeed, the light-evoked current lasted throughout even prolonged $10 \mathrm{~s}$ light steps $(n=8$ cells; Fig. $6 A$, right). We observed similar sustained synaptically driven light responses in M2 cells (data not shown), consistent with previous studies (Schmidt and Kofuji, 2009, 2010). Termination of the light stimulus in M4 cells triggered a rapid decay of the inward current and, typically, a modest outward current lasting up to several seconds. In current-clamp recordings (Fig. $6 B$ ), light stimuli drove a sustained depolarization and elevated spike frequency, and stimulus offset triggered rapid repolarization followed by a hyperpolarization during which spiking was suppressed.

Three independent lines of evidence showed that these responses were attributable to synaptic inputs driven by cones (and 


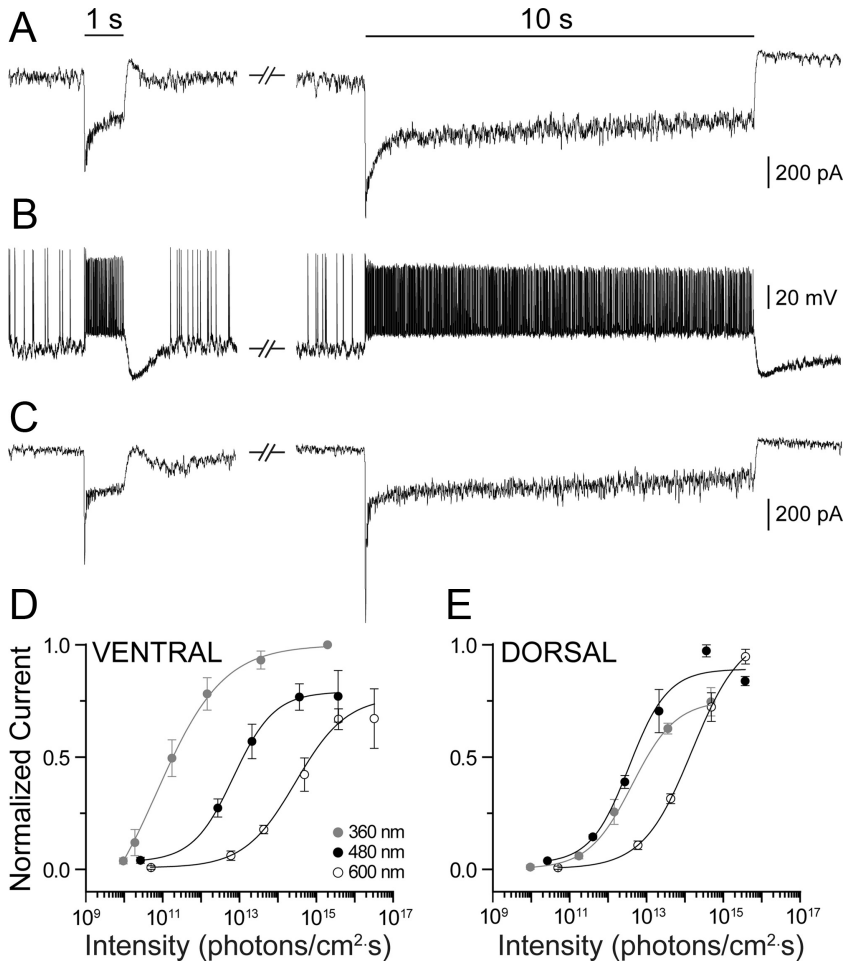

Figure 6. Functional properties of synaptic input to M4 ipRGCs. $\boldsymbol{A}, \boldsymbol{B}$, Whole-cell voltageclamp $(\boldsymbol{A})$ and current-clamp $(\boldsymbol{B})$ recordings from two representative M4 ipRGCs in response to $1 \mathrm{~s}$ (left) and $10 \mathrm{~s}$ (right) steps of $360 \mathrm{~nm}$ light used to elicit synaptic input in whole-mount $0 \mathrm{pn} 4^{\mathrm{Cre} /+} ; \mathrm{Z} / \mathrm{EG}^{+/-}$mouse retina. $C$, Whole-cell voltage-clamp recording of $\mathrm{M} 4$ cell response to $1 \mathrm{~s}$ (left) and $10 \mathrm{~s}$ (right) step of $480 \mathrm{~nm}$ light from the $0 \mathrm{pn} 4^{\text {(re/ } /(\mathrm{re} \text {; }} / \mathrm{Z} / \mathrm{EG}^{+/-}$mouse retina that lacks melanopsin and therefore represents a purely synaptically driven response. $\boldsymbol{D}, \boldsymbol{E}$, Spectral behavior of outer-retinal influence. Intensity-response relations of synaptic input to M4 cells constructed from voltage-clamp recordings in response to $1 \mathrm{~s}$ steps of light (as in $\boldsymbol{A}$, left) of different intensities at $360 \mathrm{~nm}$ (gray circles), $480 \mathrm{~nm}$ (black circles), and $600 \mathrm{~nm}$ (open circles). Data were normalized to the peak response from the most sensitive intensity-response curve from all three wavelengths, which enabled us to preserve the relative differences in maximum response amplitude evoked by the same cell at three different wavelengths. M4 cells recorded from the ventral retina $(\boldsymbol{D}, n=7)$ were more sensitive to $360 \mathrm{~nm}$ light and less sensitive to 480 $\mathrm{nm}$ light than $\mathrm{M} 4$ cells recorded from the dorsal retina $(\boldsymbol{E}, n=4)$. The intensity-response relations constructed for responses to 360,480 , and $600 \mathrm{~nm}$ were normalized to the peak response from the most sensitive intensity-response curve from all three wavelengths.

perhaps to some extent by rods) rather than to direct phototransduction. First, the responses had much shorter latencies and larger amplitudes than even saturated melanopsin-mediated intrinsic responses (Figs. 3E, 4A, B). Poststimulus recovery was also much faster. Second, these responses could be evoked by stimuli well below the threshold for melanopsin-mediated responses; for example, the stimulus evoking the responses in Figure $6 \mathrm{~B}$ was a narrowband $360 \mathrm{~nm}$ light step of $\sim 1 \cdot 10^{12}$ photons $\cdot \mathrm{cm}^{-2} \cdot \mathrm{s}^{-1}$, corresponding to an equivalent irradiance at $480 \mathrm{~nm}$ (the optimum for melanopsin) of $\sim 3 \cdot 10^{10}$ photons $\cdot \mathrm{cm}^{-2} \cdot \mathrm{s}^{-1}$, roughly $2 \log$ units below the threshold for intrinsic responses documented in Figure 4C. Finally, we recorded light-evoked currents of similar form in M4 cells from melanopsin knockout mice $\left(\mathrm{Opn} 4^{\mathrm{Cre} / \mathrm{Cre}} ; \mathrm{Z} / \mathrm{EG}^{+/-}\right)$in which intrinsic light responses are abolished (Fig. 6C).

We investigated the spectral tuning of synaptically mediated light responses in $\mathrm{M} 4$ cells from Opn $4^{\mathrm{Cre} /+} ; \mathrm{Z} / \mathrm{EG}^{+/-}$mice to assess the relative contributions of the two cone opsins. We recorded photocurrents evoked by $1 \mathrm{~s}$ steps of light (as in Fig. 6A, left) of various intensities and wavelengths (360, 480, and 600 $\mathrm{nm}$ ) from which we generated the irradiance-response functions in Figure 6, $D$ and $E$. We separately analyzed cells in the ventral $(n=7$; Fig. $6 D)$ and dorsal retina $(n=4$; Fig. $6 E)$ because of the marked differences in cone opsin expression in these retinal regions (Applebury et al., 2000) and topographical differences in spectral tuning of mouse RGCs from previous studies (Ekesten et al., 2000; Wang et al., 2011). Sensitivity to 480 and $600 \mathrm{~nm}$ stimuli (Fig. 6D, E, black and open symbols, respectively) was comparable in the two regions, with greater sensitivity of about two log units to the shorter wavelength. The response to $360 \mathrm{~nm}$ (Fig. $6 D, E$, gray symbols), however, was about two log units more sensitive in the ventral than in the dorsal retina, paralleling the higher expression levels of the S-cone opsin in this region. We observed the same spectral behavior in M2 cells $(n=3$, data not shown). This spectral behavior clearly departs from the prediction for purely melanopsin-mediated intrinsic responses, further supporting the view that these responses were synaptically mediated.

\section{Receptive field properties}

To probe receptive field organization, we exposed M4 cells to computer-generated gratings, spots, and annuli. Receptive fields were concentrically organized, with $\mathrm{ON}$ centers and antagonistic OFF surrounds. Figure 7A shows area-response functions for four M4 cells; the traces at the top display representative voltage records for one of these cells. Responses increased with spot diameters up to $\sim 300-500 \mu \mathrm{m}$ (corresponding to $\sim 10-16$ degrees of visual angle (Remtulla and Hallett, 1985) and then declined for larger spots as they encroached on the antagonistic surround. The behavior of the OFF surround was revealed in isolation by restricting illumination to the region surrounding the center (annulus inner diameter $>$ receptive field center diameter). This triggered a clear hyperpolarization at onset and depolarization and spiking at stimulus offset (Fig. $7 B$, middle trace).

When coarse sinusoidal contrast gratings were drifted across the receptive field, M4 cells exhibited strong modulations of membrane potential and spike frequency (Fig. $7 C$ ). Modulation was maximal for grating frequencies of $\sim 0.05$ cycles/degree. This is in good agreement with the dimensions of the receptive field center as assessed by the area-response measure (Fig. 7A). A halfperiod of a grating of optimal spatial frequency corresponds to $\sim 310 \mu \mathrm{m}$, which is similar to the observed optimal spot diameter of 300-500 $\mu \mathrm{m}$. M4 cells lacked any obvious directional selectivity when tested by drifting gratings (data not shown) or moving bars (Fig. 7D).

We next assessed linearity of spatial summation. To do this, we measured the response of M4 cells to instantaneous contrast reversals of gratings at various spatial phases. We expected to observe the characteristic frequency doubling (nonlinear spatial summation) that is a marker for Y-cell physiology. In pilot experiments, patterned stimuli generated with the video projector system used in Figure 7 evoked at most weak frequency doubling (data not shown). We did, however, detect robust frequency doubling using an alternative approach. We used a UV-LED driven video projector designed to stimulate both $\mathrm{M}$ - and S-opsins at a high-photopic level $\left(\sim 2.8 \times 10^{4} R^{\star} /\right.$ cone/s; see Materials and Methods). In addition, we targeted large ganglion cell somas (20-25 $\mu \mathrm{m}$ in diameter) using infrared illumination in retinas from wild-type mice, thus avoiding the pronounced adaptation resulting from epifluorescence illumination (see Fig. 5). Only cells determined to be ON-type cells from loose-patch recording were analyzed further.

A low-spatial, frequency contrast-reversing, square-wave grating evoked a dominant response at the $2 \mathrm{~Hz}$ reversal fre- 
quency (F1 amplitude) when the stimulus was in the preferred phase; that is, when one of the grating bars was centered on the receptive field (Fig. $8 A$ ). When the stimulus was shifted $90^{\circ}$ to the null phase, a frequency-doubled response dominated (F2 amplitude), indicating nonlinear spatial summation. A high-spatial frequency grating drove a F2 response at both preferred and null phases, consistent with nonlinear summation by a field of "nonlinear subunits" that extend across the receptive field (Enroth-Cugell and Robson, 1966; Hochstein and Shapley, 1976). Whole-cell recordings of excitatory currents obtained from the same cells showed that the nonlinear responses were driven by excitatory input (Fig. $8 \mathrm{~B}$ ), presumably from bipolar cells (Demb et al., 2001). In all recorded cells the F2 amplitude was independent of spatial phase, for both spikes and currents, and dominated at high spatial frequencies (Fig. $8 C$ ). The difficulty detecting the $\mathrm{F} 2$ response with the standard approach (stimulation with low UV energy after epifluorescence exposure) suggests that strong cone activation is required to generate clear nonlinear responses.

The neuron's identity as an M4 cell was tested and confirmed ( $n=8 / 8$ cells) by recording the response to a bright $10 \mathrm{~s}$ light stimulus in the presence of synaptic blockers (Fig. 8D). The peak amplitude was $65 \pm 20 \mathrm{pA}(n=6)$, which is higher than the values reported in Figure $4 B$ $(22.0 \pm 3.8 \mathrm{pA}, n=21)$. This could be a gene dose effect: wild-type mice carry two melanopsin alleles, whereas the Opn $4^{\mathrm{Cre} /+}$; $\mathrm{Z} / \mathrm{EG}^{+/-}$have only one. Each cell measured in Figure 8 showed all of the properties identified in genetically labeled M4 cells, including a lack of direction selectivity $(n=7)$, a center-surround receptive field profile $(n=7)$, a sustained response to a $10 \mathrm{~s}$ light stimulus $(n=8)$, and a wide-dendritic field (Fig. $8 D$, inset) with stratification on the vitreal side of the ON ChAT band $(n=5)$.

\section{Retrograde labeling demonstrates retinogeniculate projections of M4 ipRGCs}

The persistence of crude pattern discrimination in mice lacking functional rods and cones suggests a potential role in form vision for ipRGCs (Ecker et al., 2010). In support of this notion, anatomical studies have revealed the presence of ipRGC axonal projections to the superior colliculus and dLGN (Brown et al., 2010; Ecker et al., 2010), two retinotopically organized visual nuclei playing key roles in spatial vision. However, the specific identities of ipRGC subtypes involved in these projections are not known. To determine whether M4 cells are among the ipRGCs innervating the dLGN, we made retrograde dye injections of cholera toxin $\beta$-subunit conjugated to Alexa Fluor 594 in the dLGN of $\mathrm{Opn} 4^{\mathrm{Cre} /+} ; \mathrm{Z} / \mathrm{EG}^{+/-}$mice. We restricted our analysis to five animals in which the deposit clearly involved the ventromedial region of the dLGN, where ipRGCs preferentially project (Ecker et al.,
2010), while entirely sparing the intergeniculate leaflet, ventral lateral geniculate nucleus, or other targets of optic axons. Typical injection sites are shown in Figure 9, $A$ and $D$. Although the pipette tracks passed through the overlying optic tract, there was little apparent nonspecific labeling of passing optic axons. Involvement of optic tract axons would be expected to lead to widespread labeling throughout the retina due to the lack of topographic order in the tract; indeed, we observed global retinal labeling when deposits heavily involved the tract, and such cases were excluded from the analysis. By contrast, in the cases used for this analysis, retrograde labeling was topographically restricted (e.g., Fig. 9E) to regions predicted from the deposit's location within the retinotopic map in the dLGN (Pfeiffenberger et al., 2006). We therefore conclude that the great majority of retrolabeled cells in these experiments actually innervated the dLGN, although minor involvement of retinotectal axons lacking dLGN termination cannot be entirely excluded.

Figure $9 B$ shows a flat-mount image of the retina contralateral to the injection site in Figure 9A. In this field, there are three presumptive M4 cells (white arrowheads) identifiable by their 


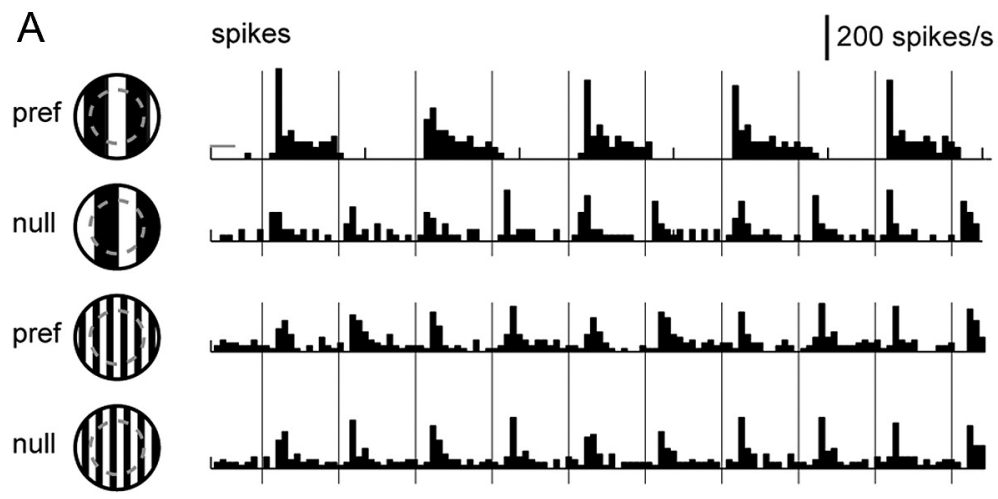

B

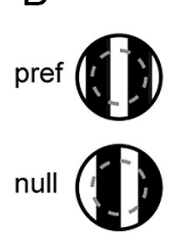

currents

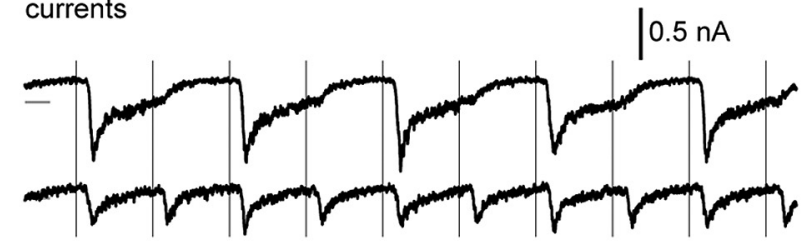

pref null

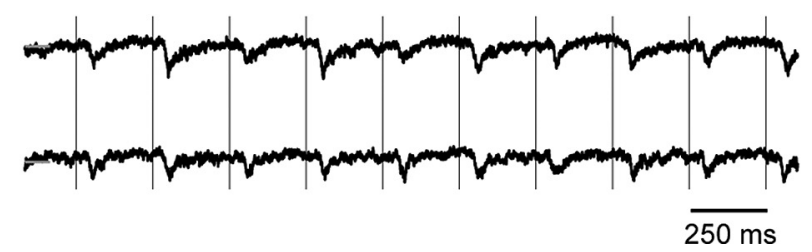

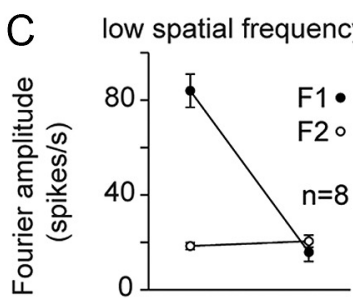

high spatial frequency
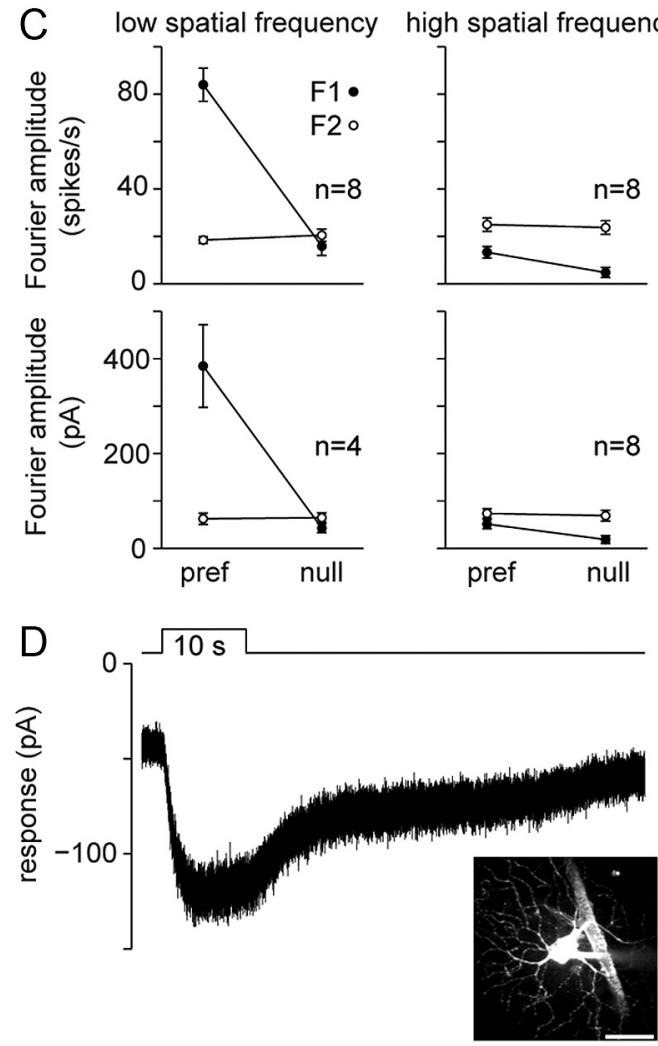

Figure 8. M4 ipRGCs are Y-cells. A, Poststimulus time histograms of the spike response to a $2 \mathrm{~Hz}$ contrast-reversing, square-wave grating at low and high spatial frequency (2 or 10 cycles/mm; 0.066 or 0.33 cycles/degree; stimulus patch, $0.63 \mathrm{~mm}$ diameter). Gratings were presented at the preferred phase (pref; grating bar centered on the receptive field) and null phase (null; grating shifted by $90^{\circ}$ with respect to pref). Histograms show the average spike response to four stimulus repeats recorded in loose-patch configuration from an $0 \mathrm{~N}$ cell with a large soma ( $\sim 20-25 \mu \mathrm{m}$ diameter) in the wild-type retina. Gray horizontal line indicates the maintained discharge to spatially uniform illumination at the mean luminance $(59 \pm 2$ spikes $/ \mathrm{s})$. Vertical gray lines indicate the time of contrast-reversal of the square-wave stimulus. $\boldsymbol{B}$, Excitatory currents recorded in whole-cell configuration from the cell shown in $\boldsymbol{A}$ (average of four repeats). $V_{\text {hold }}$ near $E_{C l}$, which was $-67 \mathrm{mV}$, series resistance $<25 \mathrm{M} \Omega$ with $50 \%$ compensation. Gray horizontal lines indicate the leak current with spatially uniform illumination at the mean luminance $(-280 \pm 47 \mathrm{pA})$. C, F1 and F2 amplitudes of the spike (top) and current (bottom) response as a function of spatial frequency and spatial phase across cells (sample size indicated in plot; error bars indicate SEM). $D$, The M4 identity of the cell shown in $\boldsymbol{A}$ and $\boldsymbol{B}$ was confirmed by blocking synaptic transmission (DNQX, D-AP5, L-AP4, SR-95531, strychnine) and recording the current response to a 10 s blue LED stimulus (450 nm peak; $6.6 \times$ $10^{17}$ photons $\left.\cdot \mathrm{cm}^{-2} \cdot \mathrm{s}^{-1}\right)$. Inset shows a two-photon fluorescence image of the cell body and dendrites, labeled by Lucifer yellow, following the recording; an auto-fluorescing blood vessel is visible to the right of the cell body. Scale bar, $50 \mu \mathrm{m}$.

large, $\mathrm{EGFP}^{+}$somata $(>19 \mu \mathrm{m}$ in diameter) (green, left). All three also contained the retrograde tracer (red, middle), indicating that these cells innervated the dLGN. We patched and dye filled such double-labeled cells and confirmed their M4 morphology and intrinsic light sensitivity in the presence of synaptic blockers $(n=3$; Fig. $9 C)$.

Although all of the large presumed M4 cells in Figure $9 B$ contained retrograde tracer, many of the smaller $\mathrm{EGFP}^{+}$somata did not. This suggests that M4 cells may be disproportionately represented among ipRGCs projecting to the dLGN. To obtain further evidence on this point, we compared the sizes of $\mathrm{EGFP}^{+}$somata with or without retrograde labeling in a region of dense retrograde cell labeling (Fig. 9E) evoked by the contralateral dLGN deposit shown in Figure 9D. Overall, approximately half of all $\mathrm{EGFP}^{+}$cells sampled contained cholera toxin (99/201 cells). The histogram of Figure $9 F$ shows that a substantial majority of the largest $\mathrm{EGFP}^{+}$cells $(>19 \mu \mathrm{m}$ diameter) were retrolabeled from the dLGN (red bars), while most of the smallest presumptive M1 cells $(<16 \mu \mathrm{m}$ diameter; see Fig. 1) lacked such labeling (gray bars). Among $\mathrm{EGFP}^{+}$cells of intermediate size, which are presumably mostly M2, M3, or M5 cells, about half of the cells were retrolabeled. Very similar results were obtained in a second experiment of the same design. We conclude that most M4 cells innervate the dLGN and that other ipRGCs types also contribute to this projection. However, M1 cells contribute relatively little to this input, as expected from an earlier study which used a genetic strategy that is now understood to have selectively labeled M1 cells (Hattar et al., 2002, 2006). The minimal labeling of M1 cells further bolsters our conclusion that passing optic tract fibers were minimally involved in these deposits, because such involvement would have been expected to label large numbers of M1 cells projecting to the OPN.

\section{Discussion}

M4 cells were originally proposed as a novel ipRGC type in a survey of EGFP-labeled cells in a sensitive melanopsin reporter mouse (Ecker et al., 2010). They were differentiated from other ipRGCs by their lack of melanopsin immunoreactivity, weak intrinsic responses, large somata, and broad dendritic arbors within the ON sublayer of the IPL. Here, using a more sensitive method, we reveal that M4 cells are melanopsin immunoreactive and stratify in a unique IPL sublamina. We show that the M4 intrinsic photocurrents are dwarfed by their brisk, sustained, synaptically mediated light responses. Their receptive fields resemble those of many conventional ON center ganglion cells, with an antagonistic OFF surround and no obvious spectral opponency or direction selectivity. We show that most M4 cells project to the dLGN 
and may thus be a major source of ipRGC influence on the visual cortex.

\section{Intrinsic photoresponses and melanopsin expression}

The initial description of M4 cells (Ecker et al., 2010) left room for doubt that they were truly autonomous photoreceptors. Although they exhibited photocurrents when glutamatergic and fast inhibitory synapses were blocked, these could have resulted from gap junctional, peptidergic, or ephaptic signaling from other ipRGCs, in which case M4 cells would be expected to lack melanopsin immunostaining. We now show by tyramide signal amplification that most M4 cells are weakly melanopsin immunoreactive, a result anticipated by an earlier report that some large ganglion cells, probably corresponding to M4 cells, were weakly stained by sensitive anti-melanopsin immunoperoxidase methods (Berson et al., 2010). Melanopsin is not merely present in M4 cells; it apparently functions, as in other ipRGCs, as their photopigment, since M4 intrinsic photocurrents have kinetics and spectral behavior resembling those in other ipRGCs (Fig. $4 A)$ and are abolished in melanopsin knockout mice (Fig. $3 F$ ).

The weakness and insensitivity of the intrinsic light response in M4 cells is probably due partly to modest levels of melanopsin photopigment. Do et al. (2009) have argued that ipRGCs are less sensitive than rods and cones, not because of reduced phototransduction gain, but because low melanopsin abundance makes photon capture less probable. Intrinsic response amplitudes parallel melanopsin expression levels among several ipRGC types; strongly expressing M1 cells exhibit much larger photocurrents than more weakly expressing M2 and M3 cells (Schmidt and Kofuji, 2009, 2011). Based on immunostaining, melanopsin expression appears even weaker in M4 than in M2 and M3 cells, and M4 cells have slightly higher intrinsic response thresholds than M2 cells. Our data may underestimate melanopsin expression and intrinsic sensitivity, because one melanopsin allele has been replaced by Cre.

\section{Relation to other ipRGC types and to alpha ganglion cells}

M4 cells are easily distinguished from other types of murine ipRGCs. Their dendritic stratification in the ON sublayer differentiates them from outer-stratifying M1 and bistratified M3 cells. Their broad, radiate dendritic profiles contrast sharply with the small, bushy profiles of M5 cells (Ecker et al., 2010). Among ipRGCs, M4 cells most closely resemble M2 cells; both
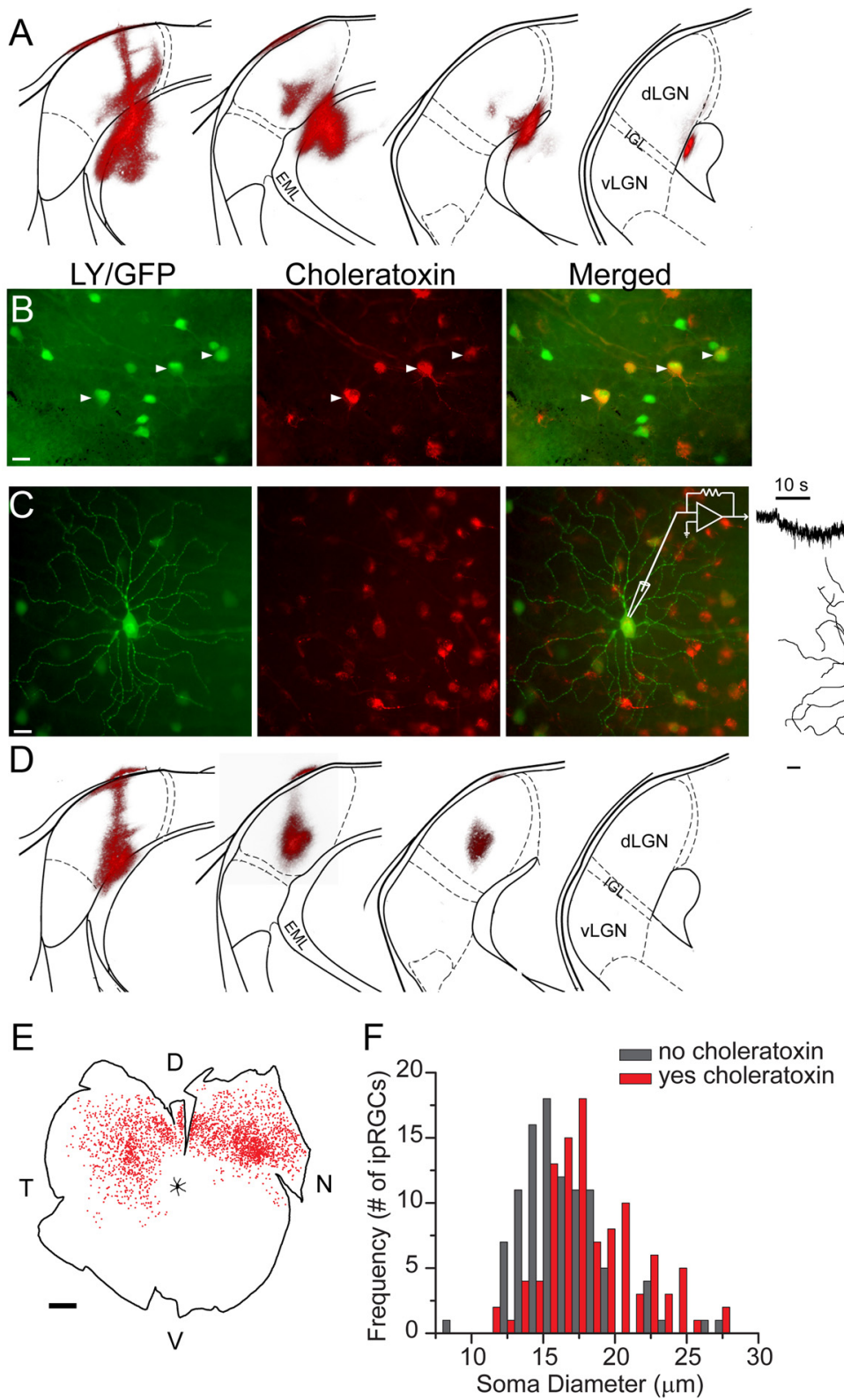

Figure 9. Retrograde labeling of M4 ipRGCs from the $\mathrm{dLGN}$ of $0 \mathrm{pn} 4^{\mathrm{Cre} /+} ; \mathrm{Z} / \mathrm{EG}^{+/-}$mice. $A$, Fluorescence image of a retrograde dye injection of cholera toxin $\beta$-subunit conjugated to Alexa Fluor 594 (red) that has been superimposed onto a schematic coronal section of the left dLGN adapted from the Paxinos and Franklin mouse atlas (Paxinos and Franklin, 2001). Sections are rostral to caudal from left to right and separated by $120 \mu \mathrm{m}$. The dLGN is the only retinofugal target involved in the deposit. The external medullary lamina (EML),although heavily involved in the deposit, lacks retinofugal fibers. $\boldsymbol{B}, \boldsymbol{C}$, Green in the left panels represents EGFP expression (both $\boldsymbol{B}$ and $\boldsymbol{C}$ ) or Lucifer yellow (LY) dialyzed through whole-cell patch-clamp recording of an M4 ipRGC (Conly) from a flat-mount retina contralateral to the dLGN injection in $\boldsymbol{A}$. Middle panels of $\boldsymbol{B}$ and $\boldsymbol{C}$ show cholera toxin (red) retrogradely labeled from the dLGN in $\boldsymbol{A}$. Right panels of $\boldsymbol{B}$ and $\boldsymbol{C}$ are red and green channels merged. Arrowheads in $\boldsymbol{B}$ indicate presumed M4 cells based on their EGFP ${ }^{+}$somata $>19 \mu \mathrm{m}$ in diameter. The cell recorded in Chad an intrinsic light response ( $7 \mathrm{pA}$ peak current; $10 \mathrm{~s}$ of $480 \mathrm{~nm}$ light) during pharmacological blockade of retinal synapses and had characteristic M4 morphology (22 $\mu \mathrm{m}$ soma diameter, $300 \mu \mathrm{m}$ dendritic field diameter, 34 branch points, and $3696 \mu \mathrm{m}$ total dendritic length). The experiment shown in $\boldsymbol{A}-\boldsymbol{C}$ was performed in a total of four animals, all with similar results. $\boldsymbol{D}$, Representative dLGN injection similar to that shown in $\boldsymbol{A}$ for a second set of experiments in which the soma sizes of cells colabeled for EGFP and cholera toxin were assessed. $\boldsymbol{E}$, Mapping of distribution of retrograde labeling in the retina contralateral to the injection in $\boldsymbol{D}$, with each red dot representing a retrolabeled soma. The retinal distribution is congruent with the retinotopic locus of the dLGN injection. The injection in the ventromedial $\mathrm{dLGN}(\boldsymbol{D}$, far left) corresponds retinotopically to dorsonasal retina. The injection extends dorsally along the medial edge of dLGN in more caudal sections that corresponds to dorsotemporal retina. $\boldsymbol{F}$, Histogram of the number of EGFP-expressing retinal ganglion cells that contained (red) or did not contain (gray) cholera toxin as a function of soma diameter, sampled from the dorsotemporal retina shown in $\boldsymbol{E}$. The majority of ipRGCs with large somata (presumptive M4 cells) were retrogradely labeled from the $\mathrm{dLGN}$, and the majority of small somata (probably mainly M1 cells) were not. The experiment shown in $\boldsymbol{D}-\boldsymbol{F}$ was performed in two animals, both with similar results. D, Dorsal; N, nasal, V, ventral; T, temporal; dLGN, dorsal lateral geniculatenucleus; $v \mathrm{VGN}$, ventral lateral geniculate nucleus, IGL, intergeniculate leaflet. Scale bars: $B, C, 20 \mu \mathrm{m} ; \boldsymbol{E}, 500 \mu \mathrm{m}$. 
have large, radiate, inner-stratifying arbors. Still, M4 differ from M2 cells on multiple dimensions, including weaker melanopsin immunoreactivity (Berson et al., 2010) and higher-threshold intrinsic responses. A transgenic reporter of melanopsin expression clearly labels M2 cells, but apparently not M4 cells (Schmidt et al., 2008). Anatomical features distinguishing M4 from M2 cells include their larger soma size, greater dendritic branching density, greater total dendritic length, and slightly more sclerad dendritic stratification (Figs. 1, 2).

M4 cells morphologically resemble a ganglion cell type previously encountered in mice (and rats) with a large soma and broad, radiate dendritic arbor stratifying in the inner half of the ON sublayer, between the ON ChAT band and the ganglion cell layer; ON alpha cells in rabbit and guinea pig stratify at the same location (Zhang et al., 2005; Manookin et al., 2008). In mice, they have been variously termed Type or Class I, ON or inner alpha, and RGA 1 cells (Sun et al., 2002), among other designations (Badea and Nathans, 2004; Coombs et al., 2006). Alpha cells have been proposed as a conserved cell type of the mammalian retina (Peichl, 1991; Berson, 2008), although more than a single pair of alpha subtypes (one ON, one OFF) have been reported in some species (Sun et al., 2002; Pang et al., 2003; Famiglietti, 2004; van Wyk et al., 2009).

\section{Synaptic responses, receptive fields, and relationship to Y-cells}

Synaptically driven responses of M4 cells are stronger and more sensitive than their direct photoresponses. Our data doubtless underestimate their magnitude, sensitivity, and dynamic range because epifluorescence scanning for EGFP clearly compromised cone and especially rod sensitivity (Fig. 5). M4 cells seem almost certain to receive a sensitive rod input. Two studies of ON-alpha (M4-like) cells (Pang et al., 2003; van Wyk et al., 2009) under more fully dark-adapted conditions than possible in our study reported sensitive rod-mediated inputs.

In many respects, $\mathrm{M} 4$ receptive fields are unremarkable. Their ON center nature is expected from their dendritic stratification in the ON sublayer of the IPL. Their spectral behavior is similar to that of most murine RGCs (Ekesten et al., 2000; Wang et al., 2011) with excitatory drive from both $S$ - and M-cone opsins, but enhanced S-cone input in the ventral retina. Their receptive fields are large, with center diameters $\sim 6-10$ degrees of visual angle, among the largest observed among murine RGCs (Koehler et al., 2011). This corresponds well with their dendritic-field dimensions, as has been observed in ganglion cells generally and alphalike cells in particular (Peichl, 1991).

M4 receptive fields exhibit substantial surround antagonism; responses are attenuated when gratings are coarser than optimal or spots extend beyond the receptive field center. Selective surround illumination triggered hyperpolarization and suppressed spiking at onset and depolarization and spike discharge at offset, confirming the presence of an OFF surround. The only prior study of receptive field structure in ipRGCs detected no such surround antagonism (Dacey et al., 2005) but was conducted in macaque retina and analyzed ipRGC types more analogous to M1 and M2 cells than to M4 cells.

Synaptically mediated responses of ipRGCs are remarkably sustained. Light steps trigger persistent inward currents and greatly elevate spike rates for stimuli up to $10 \mathrm{~s}$ long, perhaps longer. This property of M4 cells is shared with other ipRGC varieties (Dacey et al., 2005; Wong et al., 2007; Schmidt and Kofuji, 2009) and their central targets (Allen et al., 2011). The sustained nature of synaptic input to M4 cells confirms previous reports that murine $\mathrm{ON}$ alpha-like cells exhibit tonic, light- evoked depolarizations driven by sustained bipolar cell excitation (Pang et al., 2003; Murphy and Rieke, 2006; van Wyk et al., 2009). The basis of these sustained responses is unknown, but could reflect specializations of afferent bipolar cells and their modulation by amacrine cell feedback or less rapidly desensitizing glutamate receptors in the ipRGCs themselves. The tonic, light responses of M4 cells are surprising in a comparative context; M4 cells resemble $\mathrm{ON}$-alpha cells in other species, but alpha cells are transient in most species, including the cat, where they were first described (Boycott and Wässle, 1974). Cat alpha cells are clearly equivalent to the Y-cell (brisk transient) physiological type (Cleland et al., 1975), and these respond phasically to luminance steps, as do their proposed equivalents in guinea pig, gerbil, and macaque (Enroth-Cugell and Robson, 1966; Demb et al., 2001; Crook et al., 2008a,b; Luan et al., 2011). Finally, M4 cells show nonlinear spatial summation, consistent with the Y-like receptive field described in alpha cells of other species (Fig. 8).

\section{Contribution to spatial vision}

Although ipRGCs have generally been linked to such non-imageforming roles as circadian and pupillary control, M4 ipRGCs seem likely to contribute to pattern vision. Their synaptically driven light responses are brisk and, apparently (Pang et al., 2003), sensitive. Their receptive fields, with antagonistic surrounds, are well suited to enhance and encode local contrast. Most M4 cells seem to project to the dLGN, with retinotopic order (Fig. 9). Other ipRGC types also innervate the dLGN; many GFP-tagged melanopsin cells retrolabeled from the dLGN are too small to be M4; they are presumably M2 or M5 cells, since M1 cells apparently contribute little to this projection (Hattar et al., 2006; see also Fig. 9F). Retinogeniculate ipRGC terminals are restricted to a ventromedial sector of the dLGN (Brown et al., 2010; Ecker et al., 2010), much like inputs from another alpha-like ganglion cell, the OFF transient alpha cell (Huberman et al., 2008).

The spatial resolution of M4 cells is evidently lower than that of murine vision overall, as assessed electrophysiologically (Fischer et al., 2007) or behaviorally (Ecker et al., 2010). However M4 acuity roughly matches that of mice lacking functional rods and cones (Ecker et al., 2010) in which M4 cells may be the major source of retino-geniculo-cortical signals. In wild-type mice, the influence of classical photoreceptors on M4 light responses dwarfs that exerted by melanopsin. How intrinsic photosensitivity regulates the behavior of M4 cells under different lighting conditions and how such modulation may affect murine visual performance (see e.g., Brown et al., 2012) are questions worthy of further study.

\section{References}

Allen AE, Brown TM, Lucas RJ (2011) A distinct contribution of shortwavelength-sensitive cones to light-evoked activity in the mouse pretectal olivary nucleus. J Neurosci 31:16833-16843.

Applebury ML, Antoch MP, Baxter LC, Chun LL, Falk JD, Farhangfar F, Kage K, Krzystolik MG, Lyass LA, Robbins JT (2000) The murine cone photoreceptor: a single cone type expresses both $\mathrm{S}$ and $\mathrm{M}$ opsins with retinal spatial patterning. Neuron 27:513-523.

Badea TC, Nathans J (2004) Quantitative analysis of neuronal morphologies in the mouse retina visualized by using a genetically directed reporter. J Comp Neurol 480:331-351.

Baver SB, Pickard GE, Sollars PJ, Pickard GE (2008) Two types of melanopsin retinal ganglion cell differentially innervate the hypothalamic suprachiasmatic nucleus and the olivary pretectal nucleus. Eur J Neurosci 27:1763-1770.

Berson DM (2008) Retinal ganglion cell types and their central projections. In: The senses: a comprehensive reference (Masland RH, Albright TD, eds), pp 491-520. San Diego: Academic.

Berson DM, Dunn FA, Takao M (2002) Phototransduction by retinal ganglion cells that set the circadian clock. Science 295:1070-1073. 
Berson DM, Castrucci AM, Provencio I (2010) Morphology and mosaics of melanopsin-expressing retinal ganglion cell types in mice. J Comp Neurol 518:2405-2422.

Boycott BB, Wässle H (1974) The morphological types of ganglion cells of the domestic cat's retina. J Physiol 240:397-419.

Brown TM, Gias C, Hatori M, Keding SR, Semo M, Coffey PJ, Gigg J, Piggins HD, Panda S, Lucas RJ (2010) Melanopsin contributions to irradiance coding in the thalamo-cortical visual system. PLoS Biol 8:e1000558.

Brown TM, Tsujimura S, Allen AE, Wynne J, Bedford R, Vickery G, Vugler A, Lucas RJ (2012) Melanopsin-based brightness discrimination in mice and humans. Curr Biol 22:1134-1141.

Cleland BG, Levick WR, Wässle H (1975) Physiological identification of a morphological class of cat retinal ganglion cells. J Physiol 248:151-171.

Coombs J, van der List D, Wang GY, Chalupa LM (2006) Morphological properties of mouse retinal ganglion cells. Neuroscience 140:123-136.

Crook JD, Peterson BB, Packer OS, Robinson FR, Troy JB, Dacey DM (2008a) Y-cell receptive field and collicular projection of parasol ganglion cells in macaque monkey retina. J Neurosci 28:11277-11291.

Crook JD, Peterson BB, Packer OS, Robinson FR, Gamlin PD, Troy JB, Dacey DM (2008b) The smooth monostratified ganglion cell: evidence for spatial diversity in the Y-cell pathway to the lateral geniculate nucleus and superior colliculus in the macaque monkey. J Neurosci 28:12654-12671.

Dacey DM, Liao HW, Peterson BB, Robinson FR, Smith VC, Pokorny J, Yau KW, Gamlin PD (2005) Melanopsin-expressing ganglion cells in primate retina signal colour and irradiance and project to the LGN. Nature 433:749-754

Demb JB, Zaghloul K, Haarsma L, Sterling P (2001) Bipolar cells contribute to nonlinear spatial summation in the brisk-transient $(\mathrm{Y})$ ganglion cell in mammalian retina. J Neurosci 21:7447-7454.

Do MT, Kang SH, Xue T, Zhong H, Liao HW, Bergles DE, Yau KW (2009) Photon capture and signalling by melanopsin retinal ganglion cells. Nature 457:281-287.

Ecker JL, Dumitrescu ON, Wong KY, Alam NM, Chen SK, LeGates T, Renna JM, Prusky GT, Berson DM, Hattar S (2010) Melanopsin-expressing retinal ganglion-cell photoreceptors: cellular diversity and role in pattern vision. Neuron 67:49-60.

Ekesten B, Gouras P, Yamamoto S (2000) Cone inputs to murine retinal ganglion cells. Vision Res 40:2573-2577.

Enroth-Cugell C, Robson JG (1966) The contrast sensitivity of retinal ganglion cells of the cat. J Physiol 187:517-552.

Famiglietti EV (2004) Class I and class II ganglion cells of rabbit retina: a structural basis for X and Y (brisk) cells. J Comp Neurol 478:323-346.

Fischer QS, Graves A, Evans S, Lickey ME, Pham TA (2007) Monocular deprivation in adult mice alters visual acuity and single-unit activity. Learn Mem 14:277-286.

Hatori M, Le H, Vollmers C, Keding SR, Tanaka N, Buch T, Waisman A, Schmedt C, Jegla T, Panda S (2008) Inducible ablation of melanopsinexpressing retinal ganglion cells reveals their central role in non-image forming visual responses. PLoS ONE 3:e2451.

Hattar S, Liao HW, Takao M, Berson DM, Yau KW (2002) Melanopsincontaining retinal ganglion cells: architecture, projections, and intrinsic photosensitivity. Science 295:1065-1070.

Hattar S, Kumar M, Park A, Tong P, Tung J, Yau KW, Berson DM (2006) Central projections of melanopsin-expressing retinal ganglion cells in the mouse. J Comp Neurol 497:326-349.

Heikkinen H, Nymark S, Koskelainen A (2008) Mouse cone photoresponses obtained with electroretinogram from the isolated retina. Vision Res 48:264-272.

Hochstein S, Shapley RM (1976) Linear and nonlinear spatial subunits in Y cat retinal ganglion cells. J Physiol 262:265-284.

Huberman AD, Manu M, Koch SM, Susman MW, Lutz AB, Ullian EM, Baccus SA, Barres BA (2008) Architecture and activity-mediated refinement of axonal projections from a mosaic of genetically identified retinal ganglion cells. Neuron 59:425-438.

Koehler CL, Akimov NP, Rentería RC (2011) Receptive field center size decreases and firing properties mature in $\mathrm{ON}$ and OFF retinal ganglion cells after eye opening in the mouse. J Neurophysiol 106:895-904.

Kolesnikov AV, Tang PH, Parker RO, Crouch RK, Kefalov VJ (2011) The mammalian cone visual cycle promotes rapid $\mathrm{M} / \mathrm{L}$-cone pigment regeneration independently of the interphotoreceptor retinoid-binding protein. J Neurosci 31:7900-7909.

Luan L, Ren C, Lau BW, Yang J, Pickard GE, So KF, Pu M (2011) Y-like retinal ganglion cells innervate the dorsal Raphe nucleus in the Mongolian gerbil (Meriones unguiculatus). PLoS One 6:e18938.

Manookin MB, Beaudoin DL, Ernst ZR, Flagel LJ, Demb JB (2008) Disinhibition combines with excitation to extend the operating range of the $\mathrm{OFF}$ visual pathway in daylight. J Neurosci 28:4136-4150.

Murphy GJ, Rieke F (2006) Network variability limits stimulus-evoked spike timing precision in retinal ganglion cells. Neuron 52:511-524.

Nikonov SS, Kholodenko R, Lem J, Pugh EN Jr (2006) Physiological features of the $\mathrm{S}$ - and $\mathrm{M}$-cone photoreceptors of wild-type mice from singlecell recordings. J Gen Physiol 127:359-374.

Nymark S, Heikkinen H, Haldin C, Donner K, Koskelainen A (2005) Light responses and light adaptation in rat retinal rods at different temperatures. J Physiol 567:923-938.

Panda S, Nayak SK, Campo B, Walker JR, Hogenesch JB, Jegla T (2005) Illumination of the melanopsin signaling pathway. Science 307:600-604.

Pang JJ, Gao F, Wu SM (2003) Light-evoked excitatory and inhibitory synaptic inputs to $\mathrm{ON}$ and $\mathrm{OFF}$ alpha ganglion cells in the mouse retina. J Neurosci 23:6063-6073.

Paxinos G, Franklin KBJ (2001) The mouse brain in stereotaxic coordinates. San Diego: Academic.

Peichl L (1991) Alpha ganglion cells in mammalian retinae: common properties, species differences, and some comments on other ganglion cells. Vis Neurosci 7:155-169.

Pfeiffenberger C, Yamada J, Feldheim DA (2006) Ephrin-As and patterned retinal activity act together in the development of topographic maps in the primary visual system. J Neurosci 26:12873-12884.

$\mathrm{Pu}$ M, Berson DM, Pan T (1994) Structure and function of retinal ganglion cells innervating the cat's geniculate wing: an in vitro study. J Neurosci 14:4338-4358.

Qiu X, Kumbalasiri T, Carlson SM, Wong KY, Krishna V, Provencio I, Berson DM (2005) Induction of photosensitivity by heterologous expression of melanopsin. Nature 433:745-749.

Remtulla S, Hallett PE (1985) A schematic eye for the mouse, and comparisons with the rat. Vision Res 25:21-31.

Schmidt TM, Kofuji P (2009) Functional and morphological differences among intrinsically photosensitive retinal ganglion cells. J Neurosci 29:476-482.

Schmidt TM, Kofuji P (2010) Differential cone pathway influence on intrinsically photosensitive retinal ganglion cell subtypes. J Neurosci 30:16262-16271

Schmidt TM, Kofuji P (2011) Structure and function of bistratified intrinsically photosensitive retinal ganglion cells in the mouse. J Comp Neurol 519:1492-1504.

Schmidt TM, Taniguchi K, Kofuji P (2008) Intrinsic and extrinsic light responses in melanopsin-expressing ganglion cells during mouse development. J Neurophysiol 100:371-384.

Sun W, Li N, He S (2002) Large-scale morphological survey of mouse retinal ganglion cells. J Comp Neurol 451:115-126.

Van Hook MJ, Berson DM (2010) Hyperpolarization-activated current (I(h)) in ganglion-cell photoreceptors. PLoS One 5:e15344.

van Wyk M, Wässle H, Taylor WR (2009) Receptive field properties of ONand OFF-ganglion cells in the mouse retina. Vis Neurosci 26:297-308.

Viney TJ, Balint K, Hillier D, Siegert S, Boldogkoi Z, Enquist LW, Meister M, Cepko CL, Roska B (2007) Local retinal circuits of melanopsincontaining ganglion cells identified by transsynaptic viral tracing. Curr Biol 17:981-988.

Wang YV, Weick M, Demb JB (2011) Spectral and temporal sensitivity of cone-mediated responses in mouse retinal ganglion cells. J Neurosci 31:7670-7681.

Warren EJ, Allen CN, Brown RL, Robinson DW (2003) Intrinsic light responses of retinal ganglion cells projecting to the circadian system. Eur J Neurosci 17:1727-1735.

Wässle H, Puller C, Müller F, Haverkamp S (2009) Cone contacts, mosaics, and territories of bipolar cells in the mouse retina. J Neurosci 29:106-117.

Wong KY, Dunn FA, Berson DM (2005) Photoreceptor adaptation in intrinsically photosensitive retinal ganglion cells. Neuron 48:1001-1010.

Wong KY, Dunn FA, Graham DM, Berson DM (2007) Synaptic influences on rat ganglion-cell photoreceptors. J Physiol 582:279-296.

Zhang J, Li W, Hoshi H, Mills SL, Massey SC (2005) Stratification of alpha ganglion cells and ON/OFF directionally selective ganglion cells in the rabbit retina. Vis Neurosci 22:535-549. 